\title{
Model of a Generic Natural Uranium Conversion Plant-Suggested Measures to Strengthen International Safeguards
}

November 2009

From Oak Ridge National Laboratory

Ana Claudia Raffo-Caiado

John M. Begovich

Juan J. Ferrada

Jennifer Ladd-Lively

From Brazilian Nuclear Energy Commission

Marco Antonio Saraiva Marzo

Lilia Crissiuma Palhares

Fabio Cordeiro Diaz

Marcos Sodré Grund 


\section{DOCUMENT AVAILABILITY}

Reports produced after January 1, 1996, are generally available free via the U.S. Department of Energy (DOE) Information Bridge.

Web site http://www.osti.gov/bridge

Reports produced before January 1, 1996, may be purchased by members of the public from the following source.

National Technical Information Service

5285 Port Royal Road

Springfield, VA 22161

Telephone 703-605-6000 (1-800-553-6847)

TDD 703-487-4639

Fax 703-605-6900

E-mail info@ntis.gov

Web site http://www.ntis.gov/support/ordernowabout.htm

Reports are available to DOE employees, DOE contractors, Energy Technology Data Exchange (ETDE) representatives, and International Nuclear Information System (INIS) representatives from the following source.

Office of Scientific and Technical Information

P.O. Box 62

Oak Ridge, TN 37831

Telephone 865-576-8401

Fax 865-576-5728

E-mail reports@osti.gov

Web site http://www.osti.gov/contact.html

This report was prepared as an account of work sponsored by an agency of the United States Government. Neither the United States Government nor any agency thereof, nor any of their employees, makes any warranty, express or implied, or assumes any legal liability or responsibility for the accuracy, completeness, or usefulness of any information, apparatus, product, or process disclosed, or represents that its use would not infringe privately owned rights. Reference herein to any specific commercial product, process, or service by trade name, trademark, manufacturer, or otherwise, does not necessarily constitute or imply its endorsement, recommendation, or favoring by the United States Government or any agency thereof. The views and opinions of authors expressed herein do not necessarily state or reflect those of the United States Government or any agency thereof. 


\section{MODEL OF A GENERIC NATURAL URANIUM CONVERSION PLANT- SUGGESTED MEASURES TO STRENGTHEN INTERNATIONAL SAFEGUARD}

From Oak Ridge National Laboratory

Ana Claudia Raffo-Caiado

John M. Begovich

Juan J. Ferrada

Jennifer Ladd-Lively

\section{From Brazilian Nuclear Energy Commission}

Marco Antonio Saraiva Marzo

Lilia Crissiuma Palhares

Fabio Cordeiro Diaz

Marcos Sodré Grund

\section{Contributors:}

Richard Faulkner

Lisa Loden

Roger Spence

Wes Bicha

Lee Trowbridge

Joe Birdwell

Bill Del Cul

\section{November 2009}

Prepared by

OAK RIDGE NATIONAL LABORATORY

P.O. Box 2008

Oak Ridge, Tennessee 37831-6285

managed by

UT-BATTELLE, LLC

for the

U.S. DEPARTMENT OF ENERGY

under contract DE-AC05-00OR22725 



\section{TABLE OF CONTENTS}

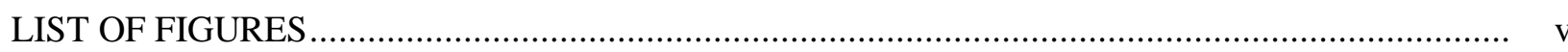

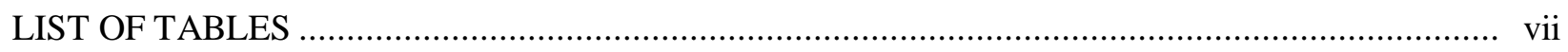

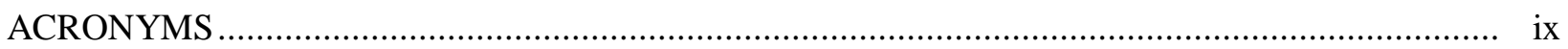

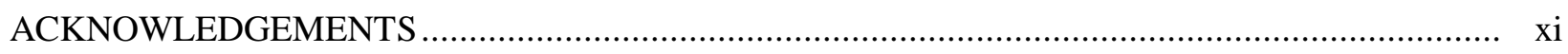

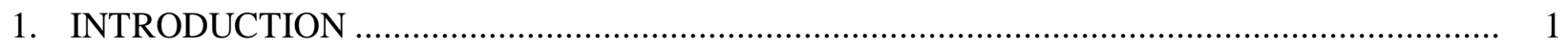

2. TECHNICAL PROCESS FOR NATURAL URANIUM CONVERSION PLANTS .................... 2

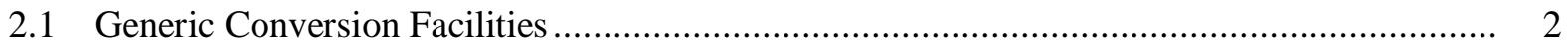

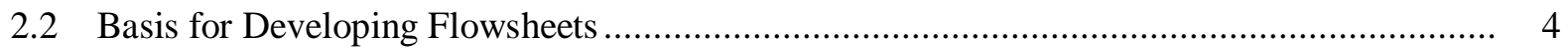

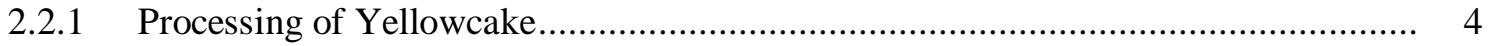

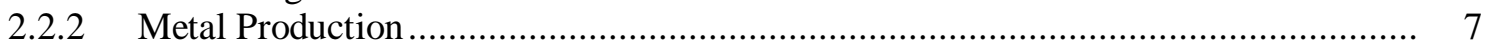

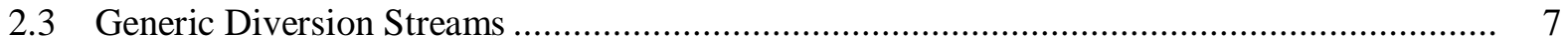

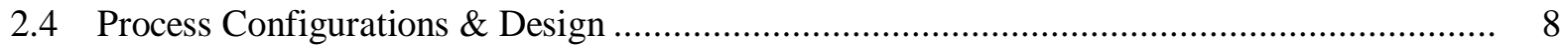

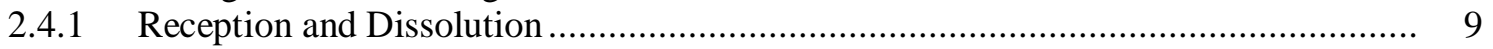

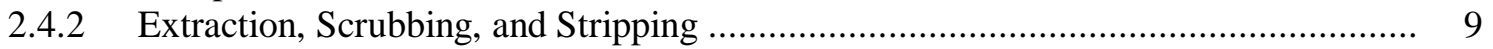

2.4.3 Evaporation and Precipitation .................................................................. 11

2.4.4 Calciner and Hydrofluorination .................................................................. 11

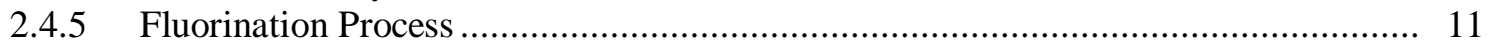

2.4.6 Complete Mass Balance Summary..................................................................... 11

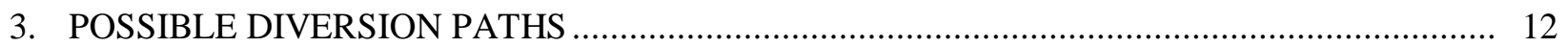

3.1 Safeguards Monitoring Techniques........................................................................ 12

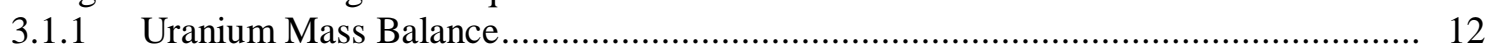

3.1.2 Monitoring Techniques - Uranium Solutions ................................................. 13

3.1.3 Monitoring Techniques - Uranium Solids ..................................................... 13

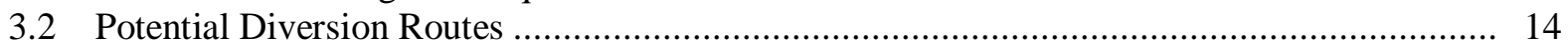

3.2.1 Introduction of Undeclared Material or Diversion of Declared

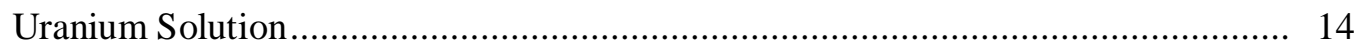

3.2.2 Other Potential Processes with Diverted Material............................................... 16

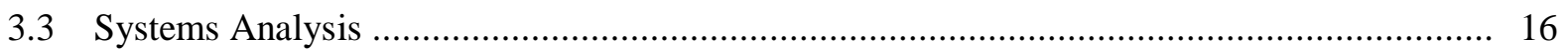

3.3.1 Division of the NUCP into Logical Process Areas for Mass Balance

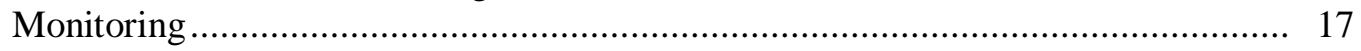

3.4 Recommended Key Measurement Points ................................................................. 18

4. DETECTION TECHNIQUES AND TECHNOLOGIES................................................ 21

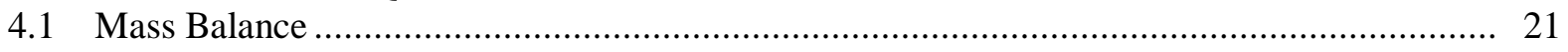

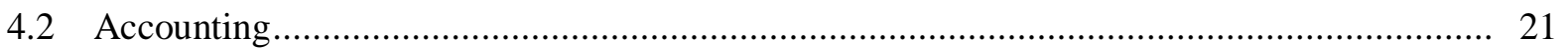

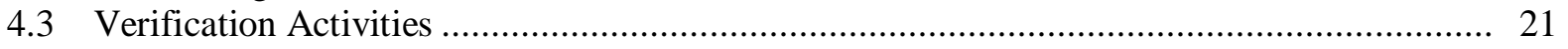

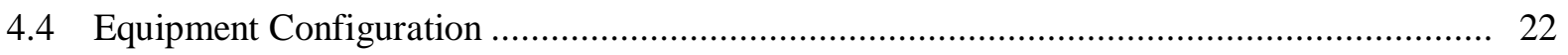

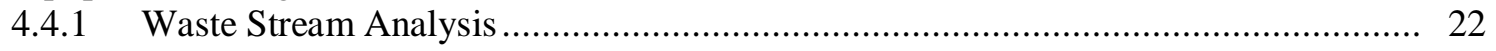

4.4.2 Needed Precision of Analytical Technique...................................................... 22

4.5 Review of Available Technologies for Process Monitoring .............................................. 22

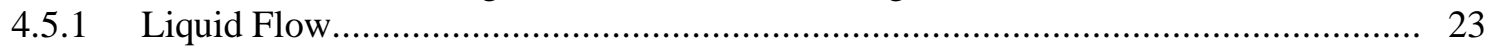

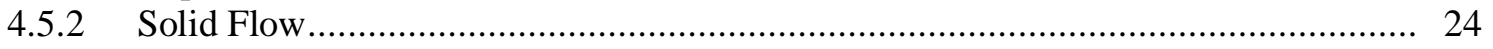

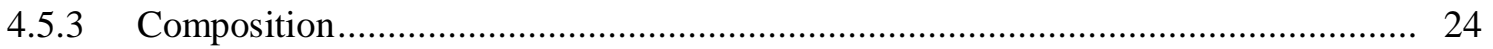




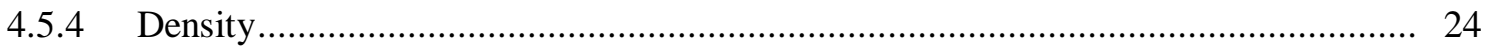

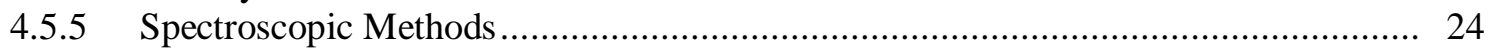

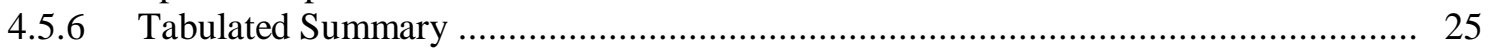

4.6 Determination of Uranium Concentration in Aqueous Nitric Acid Solutions

from Temperature, Conductivity, and Density Measurements........................................ 26

4.7 Nondestructive Assay for Analysis of Uranium Concentration for Bulk Solids..................... 26

4.8 Uranium Flow and Concentration Monitoring, Development, and Demonstration of In-Line Instrumentation in Natural Uranium Conversion Facilities ................................... 27

5. RESULTS OF JOINT EXPERIMENTS WITH FLOW METERS AND GAMMA-RAY

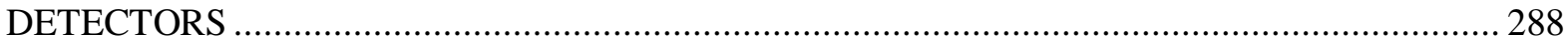

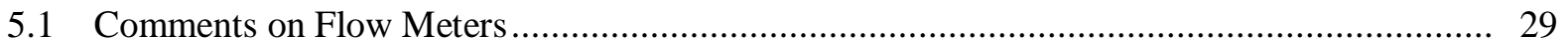

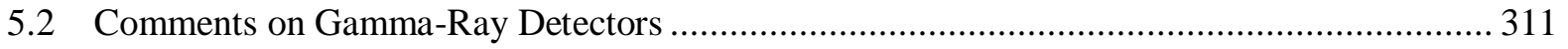

6. CONCLUSION

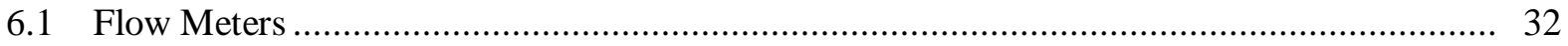

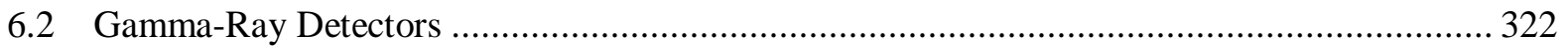

APPENDIX A — COMPARISON OF IAEA SAFEGUARDS TECHNIQUES WITH

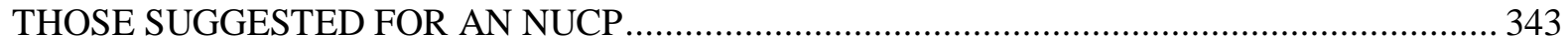




\section{LIST OF FIGURES}

Figure

Page

1. Nuclear fuel/weapons cycle................................................................................

2. Simplified flow diagram of various conversion processes ............................................... 4

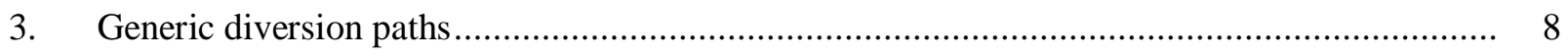

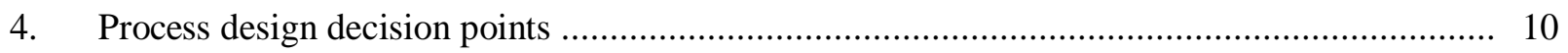

5. Sequence of stages for the natural uranium conversion plant ........................................ 11

6. The basic mass balance concept ........................................................................... 13

7. Recommended key measurement points ................................................................... 15

8. Example of a Coriolis flow measuring system …............................................................ 23

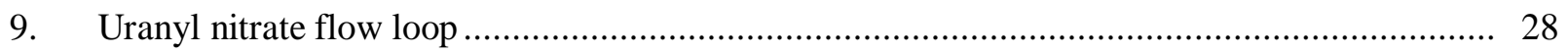

10. Setup of the flow loop at the Springfield facility ....................................................... 28

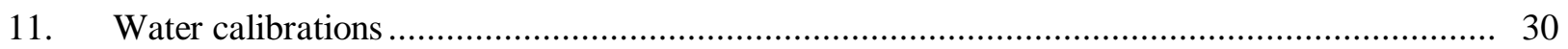

12. Comparison of Coriolis and magnetic flow measurements ........................................... 30 



\section{LIST OF TABLES}

Table

Page

1. Suggested key measurement points ......................................................................... 19

2. Safeguards for the suggested key measurement points from Table 1 ................................ 20

3. Flow rates and concentration at key measurement points D, F, and L.............................. 22

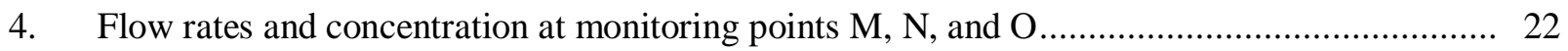

5. Flow measurement methods_applicability to key measurement points ............................. 25

6. Composition measurement methods—applicability to key measurement points .................... 25 



\section{ACRONYMS}

\begin{tabular}{|c|c|}
\hline${ }^{235} \mathrm{U}$ & uranium-235 \\
\hline${ }^{238} \mathrm{U}$ & uranium-238 \\
\hline $\mathrm{ADU}$ & ammonium diuranate \\
\hline AUC & ammonium uranyl carbonate \\
\hline AVLIS & atomic vapor laser isotope separation \\
\hline CNEN & Brazilian Nuclear Energy Commission \\
\hline DA & destructive analysis \\
\hline DBP & dibutyl phosphate \\
\hline DDA & differential die-away \\
\hline DIV & design information provision and verification \\
\hline DOE & U.S. Department of Energy \\
\hline EMIS & electromagnetic isotope separation \\
\hline GCEP & gaseous centrifugal enrichment process \\
\hline GDEP & gaseous diffusion enrichment process \\
\hline $\mathrm{HF}$ & hydrogen fluoride \\
\hline HPGe & high-purity germanium \\
\hline IAEA & International Atomic Energy Agency \\
\hline $\mathrm{LaBr}_{3}$ & lanthanum bromide \\
\hline LANL & Los Alamos National Laboratory \\
\hline MLIS & molecular laser isotope separation \\
\hline MTU & metric tons of uranium \\
\hline MTU/year & metric tons of uranium per year \\
\hline NDA & nondestructive analysis \\
\hline NUCP & natural uranium conversion plant \\
\hline ORNL & Oak Ridge National Laboratory \\
\hline PSP & plasma separation process \\
\hline $\mathrm{U}_{3} \mathrm{O}_{8}$ & triuranium octaoxide \\
\hline $\mathrm{UF}_{4}$ & uranium tetrafluoride \\
\hline $\mathrm{UF}_{6}$ & uranium hexafluoride \\
\hline UN & uranyl nitrate $\left[\mathrm{UO}_{2}\left(\mathrm{NO}_{3}\right)_{2}\right]$ \\
\hline $\mathrm{UO}_{2}$ & uranium dioxide \\
\hline $\mathrm{UO}_{3}$ & uranium trioxide \\
\hline $\mathrm{UO}_{4}$ & uranyl peroxide \\
\hline
\end{tabular}





\section{ACKNOWLEDGEMENTS}

The authors of this paper would like to acknowledge the invaluable support of Cyndee Annese and Bill U. O’Connor of the U.S. Department of Energy's National Nuclear Security Administration for the work done on a preceding study involving approaches for enhancing the safeguards of generic natural uranium conversion plants. ${ }^{1}$

\footnotetext{
${ }^{1}$ R. Faulkner et al., Natural Uranium Conversion Plant, ORNL/TM-2004/93 (Draft), April 2004.
} 



\section{INTRODUCTION}

The Brazilian Nuclear Energy Commission (CNEN) and the U.S. Department of Energy (DOE) have agreed on a collaborative effort that provides for the evaluation of measures that can strengthen the effectiveness of international safeguards at a natural uranium conversion plant (NUCP). The work is being performed by DOE's Oak Ridge National Laboratory (ORNL) and CNEN. The project foresees the development of a generic model of a NUCP by defining typical processing steps; identifying potential safeguards activities and evaluating their effectiveness, costs, and impacts to operations on a variety of options; and identifying advanced instrumentation and techniques for verification purposes.

In 2003, the International Atomic Energy Agency (IAEA) issued a revised policy concerning the starting point of safeguards at uranium conversion facilities. Before the issue of this policy only the final products of the uranium conversion plant were considered to be of composition and purity suitable for fuel fabrication or for being isotopically enriched and therefore, subject to all the safeguards procedures described in the safeguards agreements. The IAEA now considers that the uranyl nitrate solution meets the above requirement and in case there is no possibility to account this material in a particular facility, the full safeguards procedures should go upstream in the process, going eventually to the measurement of the uranium content of the yellow cake input to the process.

This policy, the IAEA Policy Paper 18, "Safeguards Measures Applicable in Conversion Plants Processing Natural Uranium”, was issued to address the interpretation that the safeguards of the front end of the fuel cycle should be enforced. This Policy Paper combined to the new strengthened safeguards measures allowed by the Additional Protocol ${ }^{2}$, has changed safeguards approaches for NUCPs.

The main points stated in the Policy Paper 18 are:

- Interpretation of the nuclear material subject to safeguards (starting point), introducing the new definition of source material including the yellow cake in such category;

- $\quad$ New requirements for Design Information Provision and Verification (DIV);

- New DIV objectives; and

- Use of a broad complementary access concept.

It is expected that the collaborative effort between DOE and CNEN will ultimately provide key technical information that can be used by the IAEA for universal applications. Although Brazil understands that the new policy established by the IAEA is beyond the framework established in the

Quadripartite Safeguards Agreement, DOE and CNEN have explored options for implementing the IAEA policy.

In this study, DOE and CNEN have modeled a generic NUCP facility created to define processing steps and typical material flows. The production capacity of the plant is defined as capable of processing $500 \mathrm{MT}$ of U per year measured as U content in the input yellowcake material to the plant.

The goal of this report is to establish the technical basis for safeguarding NUCPs. The most appropriate process configuration was extracted to constitute a process model. Based on operational characteristics of this modeled process, strategic locations for mass balance evaluations were selected. At the same time, and most importantly, an in-depth analysis of diversion scenarios was created for the conversion processes. Strategic points were identified to attempt to mitigate undetected diversion of uranium and a few candidate instrumentation systems were proposed. It creates a technical basis for selecting an effective safeguards approach, analyzing potential safeguards activities, evaluating their effectiveness,

\footnotetext{
${ }^{2}$ Model Protocol Additional to the Agreements between States and the International Atomic Energy Agency for the Application of Safeguards, INFCIRC/540 (Corrected), IAEA, 1997.
} 
costs, and impacts to operations, and identifying advanced instrumentation and techniques for verification purposes. The report will focus on technical aspects only.

\section{TECHNICAL PROCESS FOR NATURAL URANIUM CONVERSION PLANTS}

A generic production process for natural uranium conversion normally begins with yellowcake dissolution in nitric acid, followed by a solvent extraction and purification process, followed by a concentration process in an evaporator. These are three common stages to almost any NUCP. Then, one of two main routes may be followed depending on the size of the conversion plant. For small plants (approximately 100-700 MTU/year), precipitation to ammonium diuranate (ADU), ammonium uranyl carbonate (AUC), or uranyl peroxide $\left(\mathrm{UO}_{4}\right)$ is followed by calcination to uranium dioxide $\left(\mathrm{UO}_{2}\right)$. These staged processes are typically operated in batch rather than continuous mode. For medium ( $>1000$ MTU/year) and large ( $>10,000$ MTU/year) plants, a thermal denitration process to convert $\mathrm{UN}$ into uranium trioxide $\left(\mathrm{UO}_{3}\right)$ or triuranium octaoxide $\left(\mathrm{U}_{3} \mathrm{O}_{8}\right)$ is followed by an oxide reduction process to produce $\mathrm{UO}_{2}$. Then regardless of the size of the plant, the $\mathrm{UO}_{2}$ is hydrofluorinated to uranium tetrafluoride $\left(\mathrm{UF}_{4}\right)$ using hydrogen fluoride (HF). The $\mathrm{UF}_{4}$ can then be fluorinated into uranium hexafluoride $\left(\mathrm{UF}_{6}\right)$ using fluorine or reduced into uranium metal using magnesium and heat. The simulation of the process is performed using FLOW (a simulation program developed at ORNL). ${ }^{3}$

\subsection{GENERIC CONVERSION FACILITIES}

An NUCP is a vital part of the nuclear fuel cycle. This type of facility produces uranium compounds, such as $\mathrm{UO}_{2}, \mathrm{UF}_{4}, \mathrm{UF}_{6}$, and uranium metal. The products of the NUCP are typically used as feedstock for uranium enrichment facilities or for reactor fuel fabrication, but they can also be used to support a nuclear weapons program. The overall importance the NUCP plays in a country's ability to have an indigenous nuclear program is portrayed in Fig. 1.

The main purpose of an NUCP is to convert yellowcake (e.g., ADU, AUC, $\mathrm{U}_{3} \mathrm{O}_{8}$ ) to a material in a chemical and physical form that is suitable for use in a nuclear program (as shown in Fig. 1). An NUCP may also be capable of converting $\mathrm{UF}_{6}$ to other desired uranium compounds (e.g., $\mathrm{UF}_{4}, \mathrm{UO}_{2}$ ).

The term yellowcake usually refers to one of several impure uranium compounds extracted from uranium-containing ores. Regardless of its chemical form, the uranium content of yellowcake is usually expressed in terms of the equivalent amount of $\mathrm{U}_{3} \mathrm{O}_{8}$ contained in the yellowcake. Yellowcake is typically the starting input material for an NUCP. Different processing approaches are used at NUCPs throughout the world.

One of the primary processing approaches involves a "wet” process in which yellowcake is dissolved and purified using solvent extraction and then converted in a series of denitration, reduction, hydrofluorination, and fluorination steps to $\mathrm{UF}_{6}$ or uranium metal.

\footnotetext{
${ }^{3}$ FLOW is a simulation program created at ORNL for modeling nuclear and chemical processes. It is an objectoriented graphical interface in which flowsheets are represented, and mass and energy balances can be calculated. Cost and risk can also be parts of the analysis. Important features of FLOW include sensitivity and uncertainty analysis, collapsing of large flowsheets into single objects, and scripting language for easy process modeling.
} 


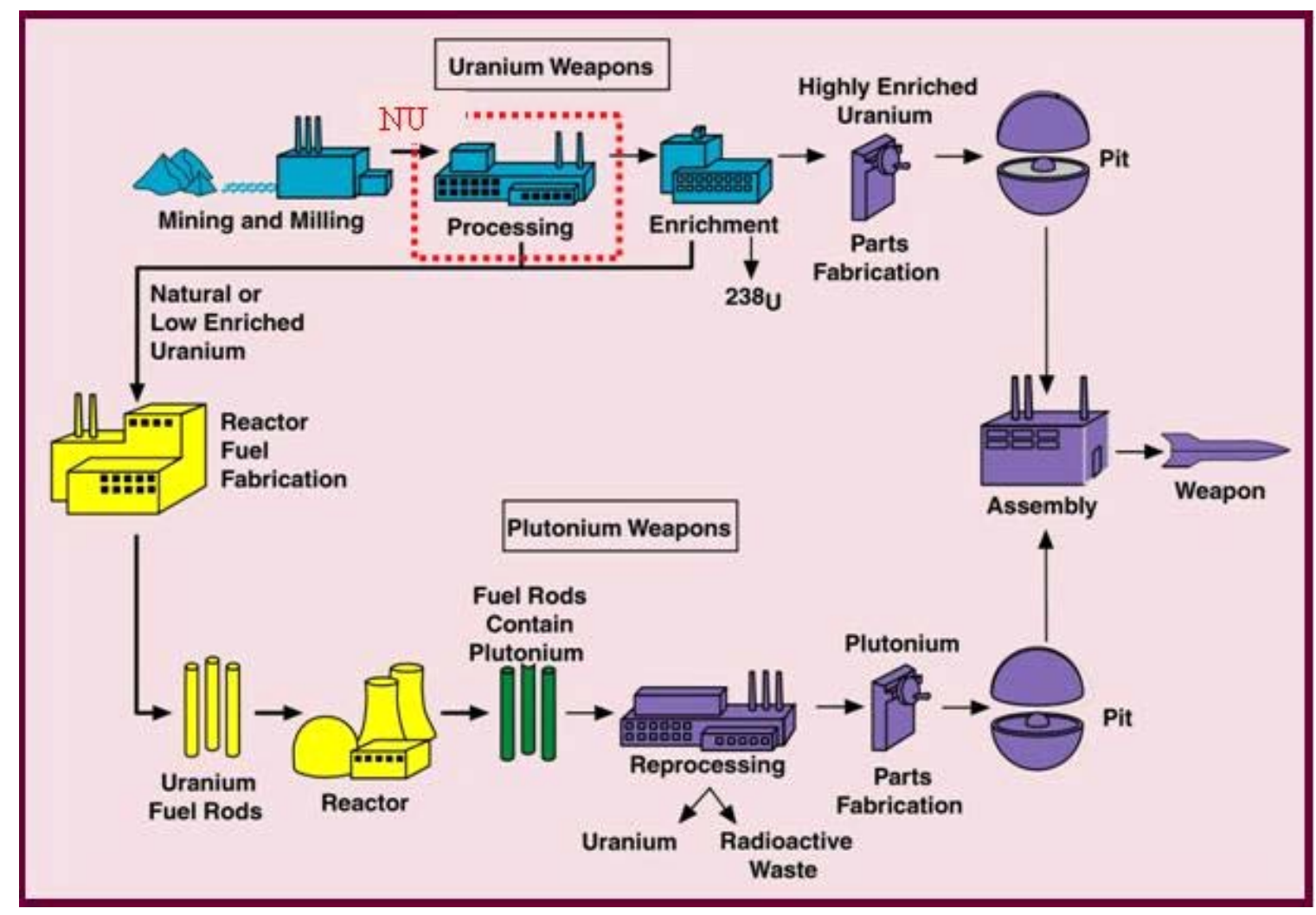

Fig. 1. Nuclear fuel/weapons cycle.

A second approach, called the "dry" process, is used where the yellowcake feed is fairly pure; thus, the dissolution and solvent extraction steps are omitted, and a fractional distillation step for final purification of the $\mathrm{UF}_{6}$ is included at the final stages of processing. A variation to the dry approach is used to convert fairly pure uranium oxides (e.g., $\mathrm{UO}_{3}, \mathrm{U}_{3} \mathrm{O}_{8}$ ) directly to $\mathrm{UF}_{6}$ through a fluorination process.

A simplified flow diagram depicting the wet process is presented in Fig. 2. This figure shows the relationship of the various individual processes that could be in operation at an NUCP in the production of $\mathrm{UO}_{2}$ and other uranium compounds, such as $\mathrm{UF}_{4}$ and $\mathrm{UF}_{6}$, as well as uranium metal. An NUCP using the wet processing path typically includes the following operations:

1. conversion of natural uranium oxides (e.g., $\mathrm{U}_{3} \mathrm{O}_{8}$, yellowcake) to $\mathrm{UN}$ solutions;

2. purification of UN solutions;

3. precipitation of purified UN solutions to a solid form (e.g., ADU, AUC, $\mathrm{UO}_{4}$ );

4. calcination of precipitates (e.g., $\mathrm{ADU}, \mathrm{AUC}, \mathrm{UO}_{4}$ ) to $\mathrm{UO}_{3}$;

5. reduction of $\mathrm{UO}_{3}$ to $\mathrm{UO}_{2}$;

6. hydrofluorination of $\mathrm{UO}_{2}$ to $\mathrm{UF}_{4}$;

7. fluorination of $\mathrm{UF}_{4}$ to $\mathrm{UF}_{6}$; or

8. reduction of $\mathrm{UF}_{4}$ to uranium metal. 


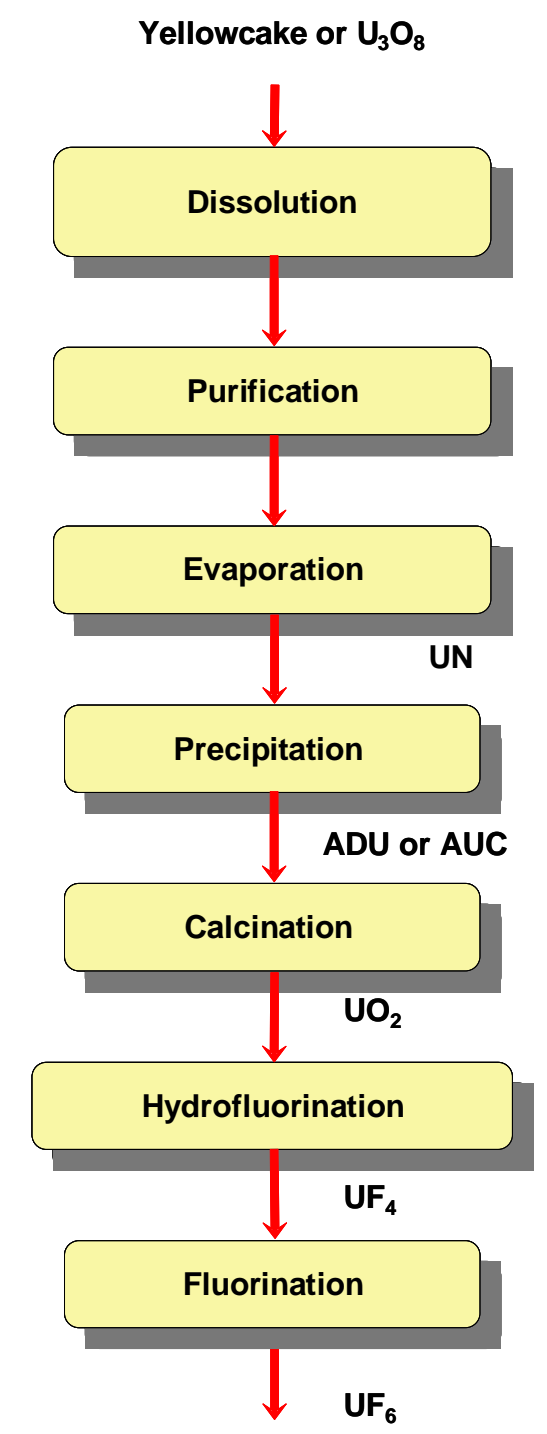

Fig. 2. Simplified flow diagram of various conversion processes.

\subsection{BASIS FOR DEVELOPING FLOWSHEETS}

Essentially, two major wet processes are used worldwide for the production of $\mathrm{UF}_{6}$ from natural uranium. Medium and large production facilities (>1000 MTU/year) typically use a thermal denitration process, while smaller units are more likely to use precipitation processes. The remainder of this report describes in various degrees of detail the precipitation processes used by small facilities ( 500 MTU/year).

\subsubsection{Processing of Yellowcake}

\section{Dissolution}

Yellowcake contains impurities at a level such that it cannot normally be used directly as feed for producing uranium compounds or metal for a nuclear program and must be purified. Purification of 
yellowcake generally starts with a dissolution process that is typically performed using nitric acid in some type of stirred, heated vessel.

The uranium concentration in the dissolver product solution is varied, depending on the downstream process requirements. Both batch and continuous modes of operation can be used in the dissolution process. The equipment used must be constructed of materials that are resistant to nitric acid corrosion (e.g., stainless steels).

\section{Purification}

The UN solution obtained from dissolution is typically purified using liquid-liquid solvent extraction. Various types of extraction equipment (e.g., mixer-settlers, pulsed columns, packed columns, mixeragitated columns, centrifugal contactors) are used.

The organic solvent that is typically used for the extraction of uranium from UN solutions is tributyl phosphate diluted in kerosene. The extraction process typically consists of three parts, each performing a different function in the purification process. The first part serves to extract the uranium from the aqueous solution into an organic phase; this section is known as extraction. The second part of purification is used to remove impurities from the uranium-bearing organic stream and is known as the scrubbing section. In the third part, uranium is stripped (back-extracted) from the scrubbed uraniumbearing organic stream back into an aqueous stream; thus, this section is known as the strip or reextraction section. Under normal operations the purified UN solution produced from the purification process contains very few contaminants. It is possible to omit the third step of purification. In that approach the organic stream is sent to a precipitation step to separate the uranium from the organic solution.

Again, because the aqueous stream containing uranium has nitric acid, the equipment used in purification must be constructed of materials that are resistant to nitric acid corrosion (i.e., stainless steels).

\section{Uranyl Nitrate Solution Processing}

The purified UN solution is converted into a solid substance, such as $\mathrm{UO}_{3}, \mathrm{U}_{3} \mathrm{O}_{8}, \mathrm{ADU}$, AUC, or $\mathrm{UO}_{4}$, using either a thermal denitration or precipitation process. The thermal denitration process is used to produce a uranium oxide (i.e., $\mathrm{UO}_{3}$ or $\mathrm{U}_{3} \mathrm{O}_{8}$ ) and is the preferred process for larger NUCPs. The precipitation process produces an intermediate material (i.e., $\mathrm{ADU}, \mathrm{AUC}$, or $\mathrm{UO}_{4}$ ) that is subsequently converted to $\mathrm{UO}_{2}$ or other oxides and appears to be the preferred process for smaller NUCPs.

\section{Precipitation}

The UN solution from solvent extraction may also be used to produce $\mathrm{UO}_{2}$ that is suitable for use in nuclear fuel. Production of $\mathrm{UO}_{2}$ for this purpose is typically done in a precipitation-type process in which ADU or AUC is formed. Uranyl peroxide is another precipitation product that can be used in the production of $\mathrm{UO}_{2}$ but has not typically been used in conversion facilities. Therefore, it will not be discussed further in this report.

ADU is precipitated from UN solution with ammonium hydroxide:

$$
2 \mathrm{UO}_{2}\left(\mathrm{NO}_{3}\right)_{2}+6 \mathrm{NH}_{4} \mathrm{OH} \Rightarrow\left(\mathrm{NH}_{4}\right)_{2} \mathrm{U}_{2} \mathrm{O}_{7}+4 \mathrm{NH}_{4} \mathrm{NO}_{3}+3 \mathrm{H}_{2} \mathrm{O}
$$

AUC is precipitated from UN solution with ammonia $\left(\mathrm{NH}_{3}\right)$ and carbon dioxide $\left(\mathrm{CO}_{2}\right)$ or ammonium bicarbonate $\left[\left(\mathrm{NH}_{4}\right) \mathrm{HCO}_{3}\right]$ :

$$
\mathrm{UO}_{2}\left(\mathrm{NO}_{3}\right)_{2}+6 \mathrm{NH}_{3}+3 \mathrm{CO}_{2}+3 \mathrm{H}_{2} \mathrm{O} \Rightarrow\left(\mathrm{NH}_{4}\right)_{4} \mathrm{UO}_{2}\left(\mathrm{CO}_{3}\right)_{3}+2 \mathrm{NH}_{4} \mathrm{NO}_{3} .
$$




\section{Uranium Dioxide Production}

As shown in Fig. 2, one of the primary products of an NUCP is $\mathrm{UO}_{2}$, which is used in reactor fuel. Uranium dioxide is also generated as an intermediate material in the NUCP in the conversion of yellowcake to $\mathrm{UF}_{4}$. It may be produced thorough calcination and reduction of precipitates (ADU or AUC) or the reduction of $\mathrm{UO}_{3}$ with hydrogen.

\section{Calcination/Reduction of Precipitates}

If the precipitation process is used, the $\mathrm{ADU}$ and $\mathrm{AUC}$ powders are readily converted to $\mathrm{UO}_{2}$ by heating (calcining) in a reducing environment (i.e., hydrogen atmosphere).

ADU generally consists of agglomerates of small, irregularly shaped crystals and is usually converted to $\mathrm{UO}_{2}$ in a calciner (rotary furnace) or a fixed-bed type of furnace. The use of fluidized beds for conversion of ADU to uranium oxides is generally not considered practical because of the poor flowability of ADU and the large amount of particles lost to the fluid bed off-gas stream. The following reaction takes place when ADU is contacted with hydrogen in a heated vessel:

$$
\left(\mathrm{NH}_{4}\right)_{2} \mathrm{U}_{2} \mathrm{O}_{7}+2 \mathrm{H}_{2} \Rightarrow 2 \mathrm{UO}_{2}+3 \mathrm{H}_{2} \mathrm{O}+2 \mathrm{NH}_{3} \text {. }
$$

AUC is a coarser, more free-flowing powder as compared to ADU. It can be calcined/reduced in a fluidized bed, as well as a rotary calciner or a fixed-bed type of furnace. The following reaction takes place when AUC is contacted with hydrogen in a heated vessel:

$$
\left(\mathrm{NH}_{4}\right)_{4} \mathrm{UO}_{2}\left(\mathrm{CO}_{3}\right)_{3}+\mathrm{H}_{2} \Rightarrow \mathrm{UO}_{2}+3 \mathrm{H}_{2} \mathrm{O}+4 \mathrm{NH}_{3}+3 \mathrm{CO}_{2}
$$

\section{Production of $\mathrm{UF}_{4}$}

Uranium tetrafluoride is an intermediate compound generated in an NUCP that is used in the production of $\mathrm{UF}_{6}$ or uranium metal. The $\mathrm{UF}_{4}$ is typically produced by reacting $\mathrm{UO}_{2}$ with anhydrous hydrogen fluoride in what is known as a hydrofluorination process. The chemical reaction that takes place in hydrofluorination is as follows:

$$
\mathrm{UO}_{2}+4 \mathrm{HF} \Leftrightarrow \mathrm{UF}_{4}+2 \mathrm{H}_{2} \mathrm{O}
$$

Different types of heated vessels, such as screw reactors, rotary calciners, fluidized beds, stirred beds, or vibrating-tray-type beds, are used in the hydrofluorination process. Because HF, which is extremely corrosive, is used in this reaction, the equipment involved in hydrofluorination must be fabricated from materials resistant to HF (e.g., Hastelloy, Monel, Inconel).

\section{Production of $\mathrm{UF}_{6}$}

Uranium hexafluoride is one of the main products of an NUCP. It is generally produced by reacting the $\mathrm{UF}_{4}$ with fluorine gas or by reacting fairly pure uranium oxides with fluorine.

The process primarily used throughout the world in the production of $\mathrm{UF}_{6}$ is the reaction of $\mathrm{UF}_{4}$ with fluorine gas. The $\mathrm{UF}_{4}$ rapidly reacts with fluorine in a highly exothermic reaction to form $\mathrm{UF}_{6}$ : 


$$
\mathrm{UF}_{4}+\mathrm{F}_{2} \Rightarrow \mathrm{UF}_{6}+\text { heat }
$$

Different types of vessels, such as a tube furnace, a vertical open-pipe reactor (known as a flame tower), or a fluidized bed can be used in this conversion of $\mathrm{UF}_{4}$ to $\mathrm{UF}_{6}$. Fluorine is an extremely corrosive gas; therefore, the equipment used needs to be fabricated from materials resistant to it (e.g., Monel, Hastelloy, Inconel).

\subsubsection{Metal Production}

Uranium tetrafluoride is readily reduced to uranium metal by reacting with either high-purity magnesium or calcium metal. The reduction of $\mathrm{UF}_{4}$ to uranium metal is typically carried out batchwise in a steel vessel that is lined with some type of refractory. The reduction requires heat to initiate. This heat is generally supplied by placing the loaded reactor vessel in an electrical or induction furnace. Presses are sometimes used to compact the $\mathrm{UF}_{4} / \mathrm{Ca}$ or $\mathrm{UF}_{4} / \mathrm{Mg}$ mixtures prior to reduction.

\subsection{GENERIC DIVERSION STREAMS}

One possible diversion point indicates that the $\mathrm{UO}_{2}$ produced in the reduction process can be sent for plutonium production (see Fig. 3). The $\mathrm{UF}_{4}$ produced in the hydrofluorination process can be reduced into uranium and directed to an atomic vapor laser isotope separation (AVLIS) process for enrichment. The $\mathrm{UF}_{6}$ produced at the fluorination stage of the process can be directed to a gaseous centrifugal enrichment process (GCEP) or a gaseous diffusion enrichment process (GDEP). The $\mathrm{UF}_{6}$ from the desublimation and fractional sublimation (or distillation) can also be sent for GCEP or GDEP enrichment. The $\mathrm{UF}_{6}$ from cylinder filling can be sent for GCEP or GDEP enrichment as well.

These diversion streams would certainly have different destinies in terms of usage. Section 5 of this report analyzes diversion paths in more detail. 


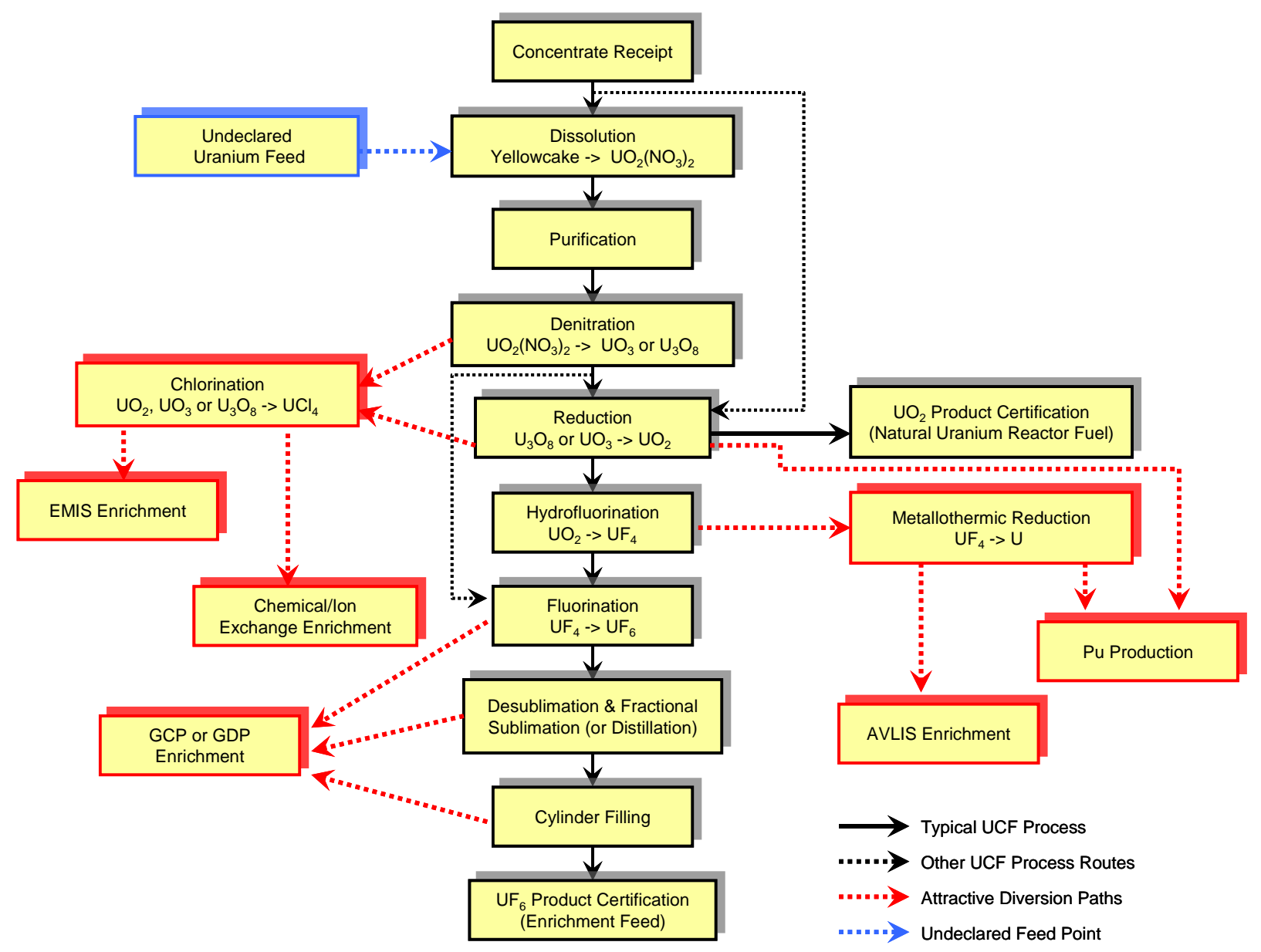

Fig. 3. Generic diversion paths.

\subsection{PROCESS CONFIGURATIONS \& DESIGN}

The definition of a conversion process is greatly determined by the size of the plant. A facility producing $100 \mathrm{MTU} /$ year is considered a small plant, while ones producing 1000 or 10,000 MTU/year are considered medium- or large-size plants, respectively. Figure 4 indicates the decision point in reference to the size of the plant.

In Fig. 4, small plants for processing levels of 100-700 MTU/year begin the route starting at point $1 \mathrm{~A}$, following with $1 \mathrm{~B}$, and then 4 . At that point the decision has to be made whether the final material is going to be $\mathrm{UF}_{6}$ (point 5) or uranium metal (point 6). If the plant is going to produce $1000 \mathrm{MTU} /$ year, then the process follows the routine beginning at $1 \mathrm{C}$, following with $1 \mathrm{D}$, and then 4 , at which stage the decision is made whether the final product will be $\mathrm{UF}_{6}$ (point 5) or uranium metal (point 6).

The flowsheet that represents the process used to convert yellowcake into $\mathrm{UF}_{6}$ is illustrated in Fig. 5 . The stages associated with this flowsheet are dissolution followed by extraction, evaporation, precipitation, conversion to oxide, conversion to $\mathrm{UF}_{4}$, and final conversion to $\mathrm{UF}_{6}$. This process configuration is particularly suitable for small plants because of the batch nature of the precipitation stage. An acid recovery facility and an organic recovery facility are two auxiliary plants typically part of the NUCP. 
For conversion plants with uranium recovery and recycle systems, uranium losses are typically low, between 2 and 3\%. Thus, for the small plant, about $488 \mathrm{MTU} /$ year (as $\mathrm{UF}_{6}$ ) will be produced from $500 \mathrm{MTU} /$ year as yellowcake. This level is designated as the normal range of plant efficiency in this study.

NUCPs may operate at lower uranium processing efficiencies when uranium losses in waste streams are less of a priority for the plant. For this study only the normal efficiencies are considered.

The NUCP selected for this study consists of several stages, starting with the reception of yellowcake and ending with the production and storage of $\mathrm{UF}_{6}$.

\subsubsection{Reception and Dissolution}

The feed material, in the form of yellowcake, is assumed to contain $85 \% \mathrm{U}_{3} \mathrm{O}_{8}$. The other $15 \%$ consists of $7.5 \%$ soluble material and $7.5 \%$ insoluble material. The process starts with stream A, feeding the plant, as shown in Fig. 5 as the starting point. Stream B represents the material from the hopper entering the dissolution process. Stream C1 is the vent from the dissolution process. After dissolution the solution is aged and resuspended in different tanks. Then it is filtered, and the filtered liquid is sent to a UN tank. Solid waste is produced at the filtration point, labeled E. Stream D, containing UN solution, is sent to a tank from which it feeds the extraction, scrubbing, and stripping processes.

\subsubsection{Extraction, Scrubbing, and Stripping}

Stream F, coming from the receiving and dissolution processes, feeds the extraction process. Stream I, the raffinate, is produced as waste material from the extraction process. The stripping process produces stream $\mathrm{M}$, which is sent to either the organic cleanup section of the process or back to the organic feed tank for the extraction column. Some uranium will be present in this organic stream; how much depends on how the reextraction column is operated. The clean material from the stripping process, labeled $\mathrm{L}$, is sent to the evaporation and precipitation processes. 
(1)

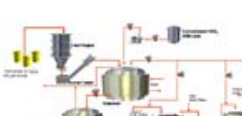
$\rightarrow i^{-1}$ $=-1 \|$

Yellowcake Dissolution<smiles>C1CCCC1</smiles>

(2)

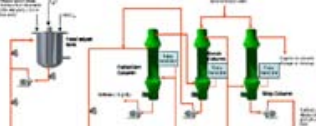

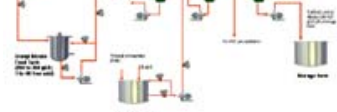

Solvent Extraction and Purification

(3)

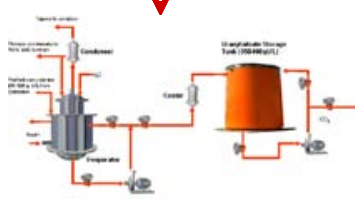

Concentration Process in an Evaporator

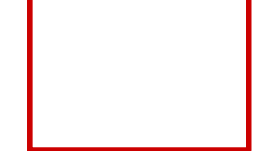

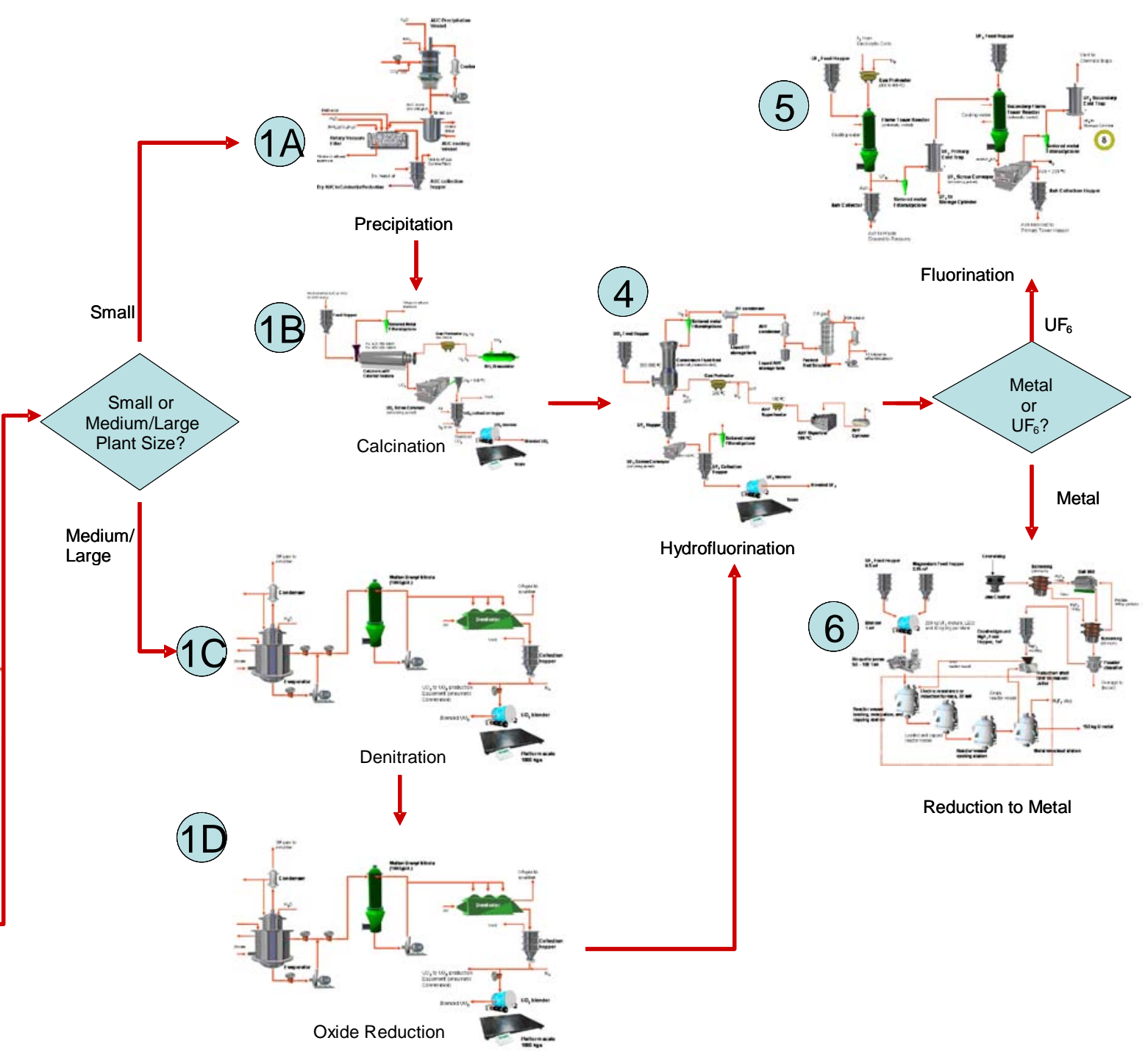

Fig. 4. Process design decision points. 


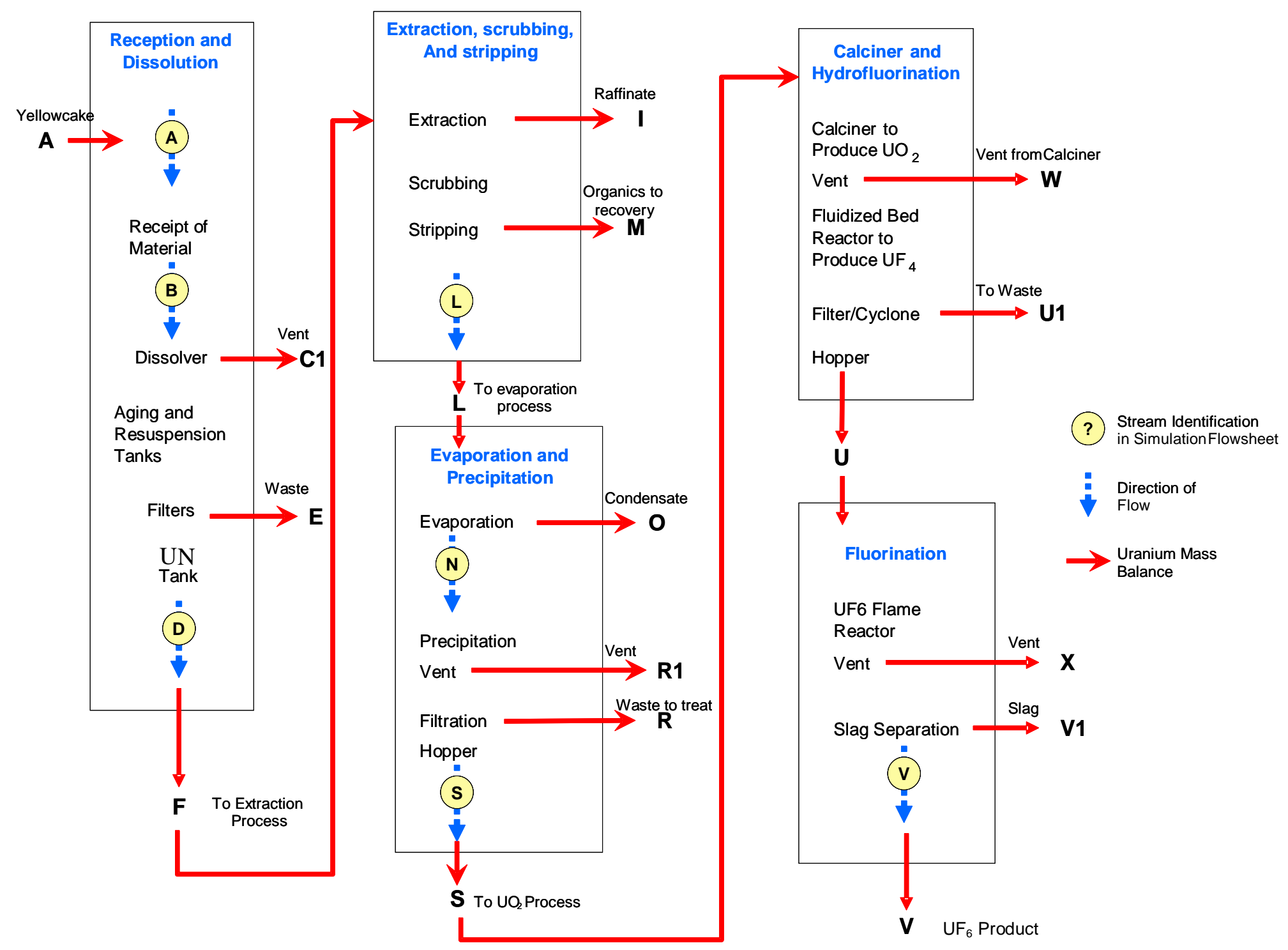

Fig. 5. Sequence of stages for the natural uranium conversion plant. 


\subsubsection{Evaporation and Precipitation}

Stream L feeds the evaporation system. Stream O is the condensate from the evaporator. Some uranium is likely to be in this stream; how much is present depends on how the evaporator is operated. The vent from the precipitation stage, labeled R1, can also contain residual uranium material. The filtration process after the precipitation stage produces a solid product and a liquid stream that is considered waste, R. Solid products from the precipitation system are sent to a collection vessel, from which they are sent to the calcining and hydrofluorination processes. Stream S takes the solid material from the hopper.

\subsubsection{Calciner and Hydrofluorination}

AUC produced in the precipitation process is fed into the calcining process, where the AUC is transformed into $\mathrm{UO}_{2}$. Stream $\mathrm{W}$ is the waste stream from the vent of the calcining process. The $\mathrm{UO}_{2}$ is then sent to a hydrofluorination fluidized-bed reactor, where $\mathrm{UO}_{2}$ is converted to $\mathrm{UF}_{4}$. Solid material contained in the fluid bed off-gas stream constitutes stream U1. This stream can either be considered a waste stream or returned to the conversion process. The $\mathrm{UF}_{4}$ is sent to a hopper, from which it feeds the fluorination process that transforms $\mathrm{UF}_{4}$ into $\mathrm{UF}_{6}$.

\subsubsection{Fluorination Process}

Stream $\mathrm{U}$ takes $\mathrm{UF}_{4}$ to the $\mathrm{UF}_{6}$ flame reactor that makes the chemical transformation possible. Vent stream X, from the flame reactor, can contain uranium material. There is a secondary flame reactor that is used to react the excess fluorine contained in the primary flame reactor's off-gas stream. Stream V1 represents the ash generated in the process and is considered a waste stream. Stream V contains the final $\mathrm{UF}_{6}$ product.

\subsubsection{Complete Mass Balance Summary}

The production capacity of the plant is defined as being capable of processing $500 \mathrm{MTU} / \mathrm{year}$ measured as uranium content in the input yellowcake material to the plant. Stream C1 takes 0.006 MTU in uraniumcontaining material. Stream E takes 1101 MTU in uranium-containing material. Stream E1 from the centrifuge takes 0.008 MTU in uranium-containing material.

Stream I, raffinate from the extraction process, takes 2.38 MTU in a uranium-containing material per year. Stream M, organic sent for recovery, takes $0.988 \mathrm{MTU}$ in a uranium-containing material. Stream R1, the vent stream, is considered to carry no uranium-containing material. Stream R, from the filtration, takes 5.16 MTU in a uranium-containing material per year. These streams could be recovered and returned to the process to minimize waste production. Stream O, from the evaporation process, takes less than 0.004 MTU in a uranium-containing material.

Stream W from the calciner venting process takes 0.528 MTU in a uranium-containing material per year. Stream U1 from the hydrofluorination venting process takes 0.526 MTU in a uranium-containing material. Stream X, the vent stream, takes 0.003 MTU in a uranium-containing material. Stream V1, the slag stream, takes $0.479 \mathrm{MTU}$ in a uranium-containing material.

The final product contains 722 metric tons of $\mathrm{UF}_{6}$ with an equivalent of $488 \mathrm{MTU}$. Consequently, the efficiency for this process is approximately $97.4 \%$.

The NUCPs operates at high efficiency. For conversion plants with uranium recovery and recycle systems, uranium losses are typically low, between 2 and 3\%. Thus, for the small plant about 488.4 MTU/ year as $\mathrm{UF}_{6}$ will be produced from $500 \mathrm{MTU} /$ year as yellowcake. 
The NUCP selected for this study consists of several stages, starting with the reception of yellowcake and ending with the production and storage of $\mathrm{UF}_{6}$, as shown in Fig. 5.

\section{POSSIBLE DIVERSION PATHS}

Uranium diversion could be attempted at certain points in a given process. Producing more uranium than is fed obviously indicates clandestine feeding of undeclared material into the process. There exists the likelihood of feeding undeclared material into the process and diverting this "extra" uranium mass before a monitoring point downstream. This fact provides a strong argument for monitoring strategic internal process points along with the yellowcake received at the conversion facility and the uranium product produced by the NUCP.

\subsection{SAFEGUARDS MONITORING TECHNIQUES}

\subsubsection{Uranium Mass Balance}

NUCPs are complex chemical processing plants that have several locations from which material can be clandestinely diverted. The NUCP can be used not only to process declared material, but also to clandestinely process undeclared material. Undeclared material may be introduced at any one of several points in the process as long as the purity and characteristics of the undeclared material are compatible with process operations at the point of introduction. Mass balance of uranium throughout the process is one of the techniques to detect the introduction of such undeclared uranium or the diversion of declared uranium. Figure 6 illustrates the principle of a mass balance in the simple terms:

In - Out = Accumulation. The solid lines in Fig. 6 represent the declared uranium flow paths; the dashed lines represent attempts to divert uranium or treat undeclared uranium.

A mass balance can be performed on the entire NUCP, any given section of the plant, or each unit and/or piece of equipment within the plant. At a minimum the uranium in the yellowcake entering the plant and the uranium in the hexafluoride product leaving the plant must be monitored. Knowing the mass of uranium entering the plant is critical to the overall mass balance or to any intermediate mass balance. Accumulating uranium for a weapons program becomes more difficult as the number of monitoring locations increases and the uranium mass within the process is followed in greater detail. Theoretically, after a process has achieved steady state, there should be no accumulation, and the uranium out should match the uranium in. Equipment failures and misoperations as well as uranium deposition (buildup of uranium deposits on walls of pipes or equipment) can result in additional accumulation and waste streams beyond those discussed in this document. Usually monitoring points are located on the main uranium product line, not in a waste stream or side stream. This approach does not allow complete closure of the mass balance. Typically the difference between the uranium mass flowing in and the uranium mass flowing out as the main product is assumed to be in these wastes or side streams, providing a means to disguise diversion. The percentage diverted is directly dependent on the size of the NUCP. For example, the IAEA trigger limit of $10 \mathrm{MTU} /$ year is $2 \mathrm{wt} \%$ of the $500 \mathrm{MTU}$ annual production capacities. A diversion of $2 \mathrm{wt} \%$ is significant and probably detectable by existing in-line analytical techniques. Knowledge of the expected process efficiency and uranium content in such uranium flows outside the main process stream is needed to help identify diversion attempts. Usually the purity of the undeclared material dictates at what point in the process it can be introduced, and the material must be processed through several unit operations for it to be useful for any weapons program. 


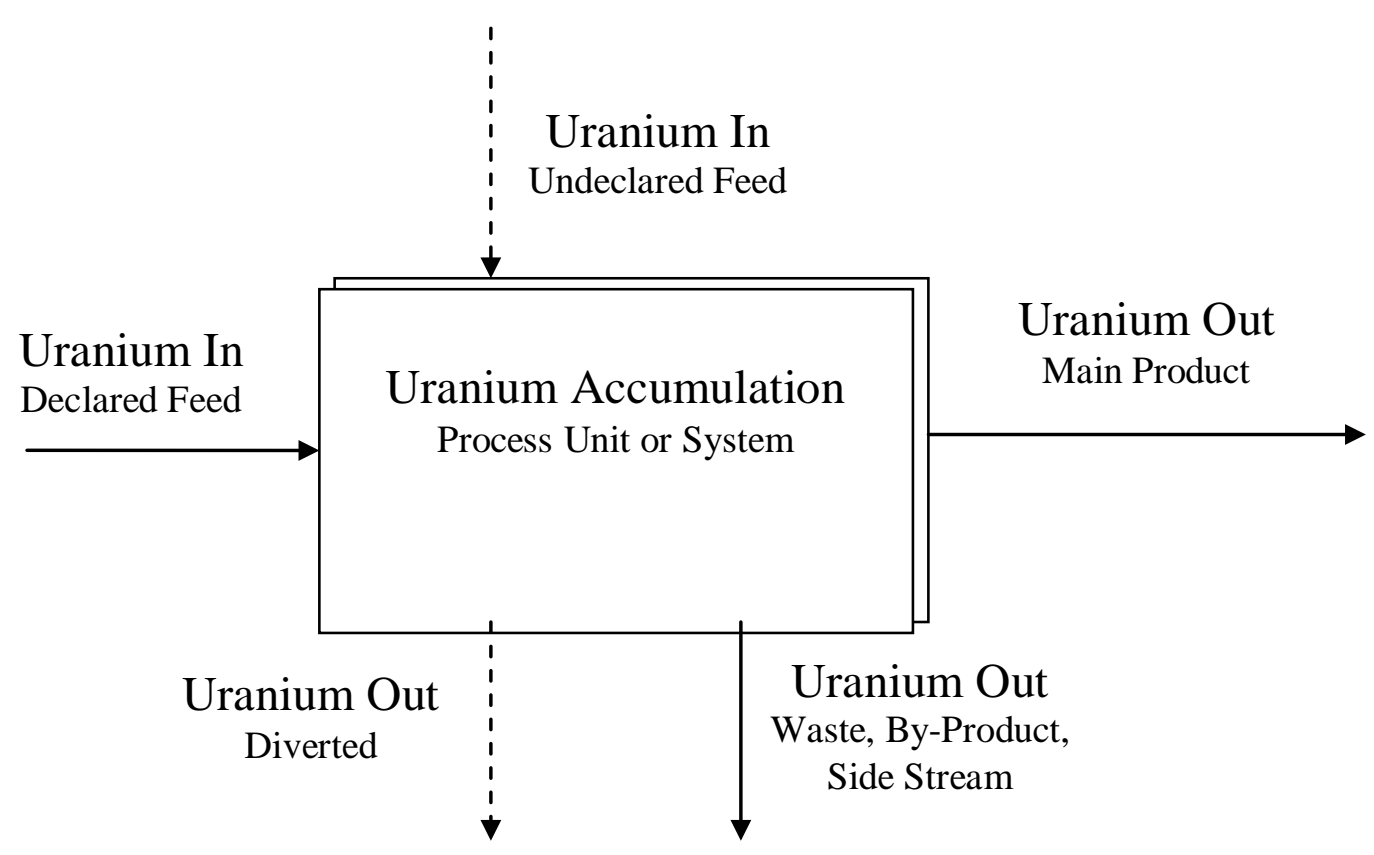

Fig. 6. The basic mass balance concept.

\subsubsection{Monitoring Techniques - Uranium Solutions}

Real-time, in-line monitoring may be practical for a uranium solution, that is, after the uranium is extracted from the yellowcake and before the uranium is changed into a solid again. There are several locations in the process at which monitoring could be done. Such monitoring requires the liquid flow rate (typically volume per unit time) and uranium concentration (mass per unit volume). Other liquid properties (e.g., density, $\mathrm{pH}$ ) can also be monitored to help verify process operation and parameters. In-line monitoring of liquid density is now readily available and can help double-check the uranium concentration and solutions. For a given solution, the density is a function of the uranium concentration. However, the primary monitoring should be a direct measurement of the uranium concentration and flow rate. Density is secondary, but it may be a property easily monitored using readily available commercial equipment. Density can be used to verify that the primary monitoring is working properly. In-line flow rate and density meters are readily available commercially. Such meters for uranium concentration are more problematic. The low uranium concentrations result in impractical count times for the low-energy gamma from radioactive decay daughters. Photometric meters for in-line measurement of uranium concentration exist, but matching safeguard needs with instrument capabilities is yet to be done. Selecting monitoring points at which higher concentrations are expected (e.g., after evaporators) would help.

\subsubsection{Monitoring Techniques - Uranium Solids}

In-line monitoring of uranium is impractical for a solid material stream, even if permissible. Gravimetric feeding of solids accompanied by real-time recording of the mass fed per unit time is possible. In addition, it is necessary to know the uranium assay of the yellowcake being fed into the dissolver to obtain the uranium mass fed per unit time into the dissolver. This task requires taking grab samples at regular intervals followed by destructive analysis (DA) of the uranium concentration. Gamma spectroscopy of the low-energy gamma from the uranium decay daughters is being used with good success for qualitative, semiquantitative, and even quantitative analysis, especially with regard to the relative ratio of uranium-235 $\left({ }^{235} \mathrm{U}\right)$ and uranium-238 $\left({ }^{238} \mathrm{U}\right)$. 
However, it is questionable whether this technique or others will provide practical real-time monitoring of the uranium concentration in a process flow of a solid material with the precision and accuracy required for detecting undeclared production. A gravimetric feed and monitoring system may provide the total mass per unit time, but grab sampling and analysis would still be required to obtain the uranium mass per unit time. In addition, the facility's accountability records (e.g., number of drums and their weights with the date and time filled) can be verified using on-site monitoring (e.g., cameras), random checking of drum weight, and a sampling program for the uranium concentration.

\subsection{POTENTIAL DIVERSION ROUTES}

Figure 3 illustrates a process flowsheet to convert natural uranium into the $\mathrm{UF}_{6}$ product required for enrichment. A typical NUCP process is given by simple vertical progression of each process box, from receipt of solid yellowcake concentrate through its dissolution by nitric acid, denitration (precipitation or thermal denitration), reduction to $\mathrm{UO}_{2}$, and finally fluorination into $\mathrm{UF}_{6}$. Possible diversion routes are shown at several locations in the flowsheet. As can be seen in Fig. 3, the natural uranium becomes attractive for diversion after purification and denitration; therefore, establishing a high level of confidence among the feed mass balance, purified mass, and product mass is critical to detecting undeclared nuclear activities.

\subsubsection{Introduction of Undeclared Material or Diversion of Declared Uranium Solution}

One clandestine objective may be to use equipment in the NUCP to process undeclared material for a weapons program with diversion prior to any monitoring points to avoid detection. Extra uranium mass could be introduced at almost any point in the process, depending on the form and purity of the undeclared material. The most likely scenario appears to be introduction of undeclared yellowcake, either in drums not in the declared accountability data or as hidden uranium mass (e.g., higher uranium assay than reported or lower drum tare weight than normal) in the drums that are part of the declared accountability data. Figure 8 illustrates the monitoring points suggested to control the material balance of uranium in the NUCP. The first monitoring point is the declared yellowcake received at the plant for processing. In-process monitors anywhere downstream after the yellowcake is dumped into the feed hopper and processed may verify the records of the mass of declared uranium feed received over time.

Several opportunities exist to monitor downstream receipt of the yellowcake. The $\mathrm{UF}_{6}$ produced by the NUCP should be monitored. Comparison of the record of the uranium mass exiting the plant in the product (point 8 in Fig. 7) with the record of the uranium mass entering the plant in the feed (yellowcake, point 1 in Fig. 7) provides the means for an overall plant uranium mass balance (minus the uranium leaving as waste). Thus, at a minimum the uranium feed entering the plant and the uranium product exiting the plant should be monitored. Producing significantly more uranium in the product than is fed is an obvious indication that undeclared feed is being introduced into the process. Detection of undeclared feed processing by monitoring input and output accountability data, supplemented with random surveillances, is possible but problematic. Discovery depends on the frequency of undeclared feed processing; the freedom of the IAEA inspector to check for this type of activity; the complexity and size of the plant; the level of underutilization of the processing equipment; and most disturbingly, the ingenuity of facility personnel. Real-time process monitors that can compare NUCP accountability data with actual process data can be very useful, especially if the software can indicate trends in the relationship of accountability and actual data using statistical control charts to document anomalies. All plants operate with some loss of raw material in the waste streams. In other words, $100 \%$ of the uranium mass in the feed is not expected in the product.

If the uranium mass lost in the waste stream is not monitored, then some idea of processing efficiency must be known to detect either introduction of undeclared uranium mass into the process or diversion of uranium mass from the process for a clandestine weapons program. A uranium mass produced that is 
greater (clandestine feed) or less (diversion) than the mass expected (within normal experimental error) from a given feed mass raises suspicions about a possible clandestine weapons program. Inaccurate measurements can result in such discrepancies, so such results alone are not necessarily definitive proof. However, they do indicate that closer scrutiny may be required in an attempt to discover and eliminate the source of the discrepancy, whether it arises from inaccurate measurements, process upsets, or a clandestine weapons program. The yellowcake fed from the feed hopper into the dissolver (point 2 in Fig. 7) is the first opportunity in the process to verify the uranium mass recorded in the accountability data for the yellowcake received at the NUCP.

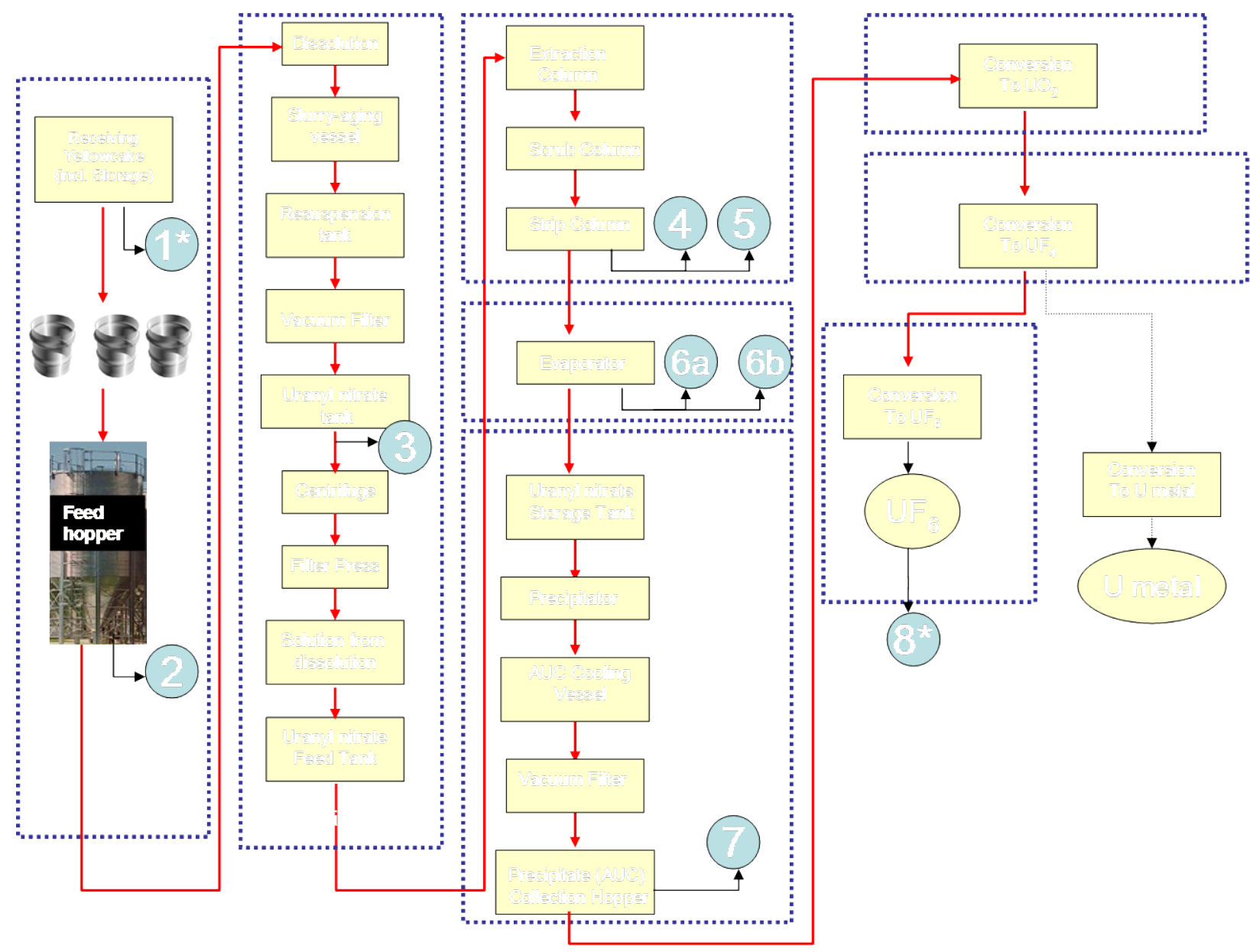

Fig. 7. Recommended key measurement points.

One possible monitoring location just after dissolution is downstream of the UN tank (point 3 in Fig. 7). Two other good locations for monitoring the uranium solution are the exit streams from the strip column just after solvent extraction (purification) and downstream of the evaporator just prior to denitrification and changing into a solid. Both the aqueous strip solution loaded with uranium (point 4 in Fig. 7) and the organic stripped of uranium exiting the strip column (point 5 in Fig. 7) should be monitored. Monitoring the aqueous strip solution provides a verification point for the uranium mass balance on the main uranium process stream after dissolution and purification.

Monitoring the organic stream verifies the efficiency of the solvent extraction process and provides mass balance closure on this process to help prevent diversion of uranium hidden by some means in the existing organic stream. The concentrated solution from the evaporator appears to be a good point for the last monitoring location of the solution prior to precipitation. Monitoring can be done at one of two locations: (1) just outside the evaporator before the pump (point 6a in Fig. 7) or (2) downstream of the reflux lines and valves, but before the cooler 
(point 6b in Fig. 7).

In summary, the flowing liquid streams are easily diverted, but they are also more amenable to in-line, real-time monitoring. Hence, four monitoring points are suggested for the liquid uranium solutions, with two of these being the locations at which the aqueous and organic streams exit the strip column. Diversion of uranium solution will still require the same processing that is done farther downstream in the NUCP, making the uranium solution a less attractive diversion target than the solid uranium oxide or uranium fluoride products produced downstream. Still, these monitoring points will help prevent the introduction of clandestine feeds and diversion prior to precipitation.

\subsubsection{Other Potential Processes with Diverted Material}

Uranium chloride is a feed for some enrichment technologies (electromagnetic isotope separation [EMIS] and chemical/ion exchange). The UN solution can be converted into uranium chloride, but diversion is more attractive after purification and denitration. Thus, diversion of one of the oxides (i.e., $\mathrm{UO}_{2}, \mathrm{UO}_{3}$, or $\mathrm{U}_{3} \mathrm{O}_{8}$ ) appears more likely (see Fig. 3), although diversion of AUC is also possible. Further processing is required to convert whichever compound is diverted into the chloride, for example, redissolving solid $\mathrm{UO}_{2}$ with hydrochloric acid:

$$
\mathrm{UO}_{2}+4 \mathrm{HCl}(\mathrm{aq}) \rightarrow \mathrm{UCl}_{4}+2 \mathrm{H}_{2} \mathrm{O}
$$

The acidic chloride solution can be used for chemical/ion-exchange enrichment, but the uranium chloride must be solidified for EMIS.

Uranium metal is a feed for plutonium production and other enrichment technologies (AVLIS and plasma separation process [PSP]). In this case, diversion of $\mathrm{UF}_{4}$ after hydrofluorination of $\mathrm{UO}_{2}$ is the probable path to clandestine uranium metal production (see Fig. 3). Metallothermic reduction converts the diverted $\mathrm{UF}_{4}$ into uranium metal:

$$
\mathrm{UF}_{4}+2 \mathrm{Mg} \rightarrow \mathrm{U}+2 \mathrm{MgF}_{2}
$$

The uranium metal can then be used in plutonium production through neutron capture or as the source of uranium vapor for enrichment in AVLIS.

Gaseous $\mathrm{UF}_{6}$ is a feed for several enrichment technologies (GDEP, GCEP, molecular laser isotope separation [MLIS]). In this case, diversion of $\mathrm{UF}_{6}$ could most likely occur after fluorination of $\mathrm{UF}_{4}$. It could happen during the fluorination process, desublimination and fractional sublimination process, or cylinder-filling process (see Fig. 3). The diverted material could be used in the enrichment process without any further processing.

Monitoring solids is not as easy as monitoring liquids. However, it is advisable to have at least one monitoring point after precipitation of the uranium to check for diversion between the solvent extraction purification and precipitation and to check for diversion between precipitation and the existing accountability data on the $\mathrm{UF}_{6}$ product. A monitoring point is suggested between the precipitate collection hopper and the process converting the precipitate to $\mathrm{UO}_{2}$ (point 7 in Fig. 7).

\subsection{SYSTEMS ANALYSIS}

Realistically, every stream cannot be monitored to independently verify mass balances around every operating unit and/or piece of equipment. On the other hand, monitoring fewer points increases opportunities for successful diversion. Thus, identifying key points at which to monitor the process is 
critical in efforts to detect either diversion of declared uranium or use of the NUCP to process undeclared uranium. Materials diverted from the NUCP will likely be in a form (e.g., oxides, $\mathrm{UF}_{4}, \mathrm{UF}_{6}$, metal) that is readily introduced into the downstream fuel-cycle processes (fuel fabrication or enrichment plants). If liquid is diverted from the NUCP, duplicate processing is required to produce material suitable for fuel fabrication and/or enrichment. On the other hand, diversion of the liquid following purification is a special concern because this is the last liquid processing step before conversion to a solid during denitration. In general, real-time monitoring is possible for the uranium solutions, but these solutions are not as attractive for diversion as the solid product, which is not as amenable to real-time monitoring. Monitoring points implemented in an NUCP need to ensure that the desired diversion materials are bounded.

The methodology used in analyzing the risks of diversion consisted of the following:

1. Dividing the detailed flowsheet into the following process areas (see Fig. 7): receipt of material, dissolution, extraction, evaporation, uranium oxide conversion to $\mathrm{UF}_{4}, \mathrm{UF}_{4}$ conversion to $\mathrm{UF}_{6}$, and $\mathrm{UF}_{4}$ conversion to uranium metal.

2. Analyzing the following four categories of diversion for each process area:

a. Material substitution: Substitution of feed materials that have higher uranium content than declared or the clandestine removal of uranium-bearing material in exchange for materials of similar characteristics (e.g., density, volume, mass) but with less or no uranium content. It is the uranium concentration and mass that are important for monitoring diversion, not total mass or rates.

b. Equipment alteration: Addition of bypass piping, valving, or other equipment used to clandestinely divert or introduce materials or modification to equipment (e.g., heating), resulting in incomplete conversions or inefficient operation with excess uranium in the waste or tails.

c. Operation: Intentionally operating processes inefficiently so that more uranium is contained in recycle, sample, or waste streams.

d. Other: Keeping two records of operation with one showing less throughput than actually processed and then declaring understated records to inspectors.

Incomplete or inaccurate records are a concern for each processing operation. Independent verification of facility records of how much uranium is processed and where it goes is an obvious need.

\subsubsection{Division of the NUCP into Logical Process Areas for Mass Balance Monitoring}

\section{Receipt of Material}

Undeclared uranium can be introduced into the plant by any one of several possible schemes and diverted prior to reaching an accountability point. Closing a mass balance requires accuracy not only on what is measured in the plant, but also on what the plant receives. An understatement of what is received means diversion before the first point of verification downstream is unlikely to be detected. In fact, such deception on the front end could allow diversion around each point of verification and use of the equipment to process the undeclared material.

\section{Dissolution}

Once again, the introduction of extra undeclared uranium into the dissolver is a concern. However, inefficient operation (intentional or not) is also a potential diversion pathway. 


\section{Extraction Purification}

The concerns in this case are added undeclared uranium to the feed stream, diversion of uranium solution, and inefficient operation.

\section{Evaporation}

As with extraction, processing diverted uranium or diversion of uranium is possible by adding uranium to the feed and/or diverting some uranium solution.

\section{Oxide to Uranium Tetrafluoride}

Diversion risks exist by substitution of material and inefficient/misoperation of equipment.

\section{Uranium Tetrafluoride to Uranium Hexafluoride}

Diversion risks exist by substitution of material and inefficient/misoperation of equipment.

\section{Uranium Tetrafluoride to Metal}

Diversion risks exist by substitution of material and inefficient/misoperation of equipment.

\section{Key Measurement Points Suggested from the Systems Analysis}

Table 1 lists the recommended key measurement points in the process flowsheet for safeguards purposes resulting from combining points of diversion with the systems analysis of the diversion pathways. These recommended strategic points are shown in Fig. 7. (Each key measurement point number is shown in a circle.)

\subsection{RECOMMENDED KEY MEASUREMENT POINTS}

In summary, the attractive routes shown in Fig. 3 consist of diverting the following:

1. $\mathrm{UO}_{2}, \mathrm{UO}_{3}$, or $\mathrm{U}_{3} \mathrm{O}_{8}$ for chlorination and enrichment by EMIS or chemical/ion-exchange processes;

2. natural uranium reactor fuel for plutonium production;

3. $\mathrm{UF}_{4}$ for reduction to uranium metal and plutonium production or enrichment by AVLIS or PSP; and

4. $\mathrm{UF}_{6}$ for enrichment by GCEP, GDEP, or MLIS.

The two largest uranium losses in the NUCP are estimated to be the following:

1. uranium remaining with the filtered solids after dissolution (probably insoluble uranium trapped in a silicate matrix) and

2. uranium in vent gases (uranium in the dust/mist from the dissolver or from handling the solid uranium powders, $\mathrm{AUC}, \mathrm{UO}_{3}, \mathrm{UO}_{2}$ )

These waste streams are logical strategic points to consider or for inspector analysis to check or verify mass balances. Losses can be minimized by recapturing and recycling, but $100 \%$ of the uranium cannot be recovered, whether it is the ore being extracted or aerosols being captured. In general the effort to capture and recycle material depends on its value. Natural uranium is not considered valuable compared to enriched uranium, but an overall efficiency exceeding $95 \mathrm{wt} \%$ is considered reasonable for the NUCP (i.e., $>475 \mathrm{~kg}$ of uranium is expected to exit the plant as $\mathrm{UF}_{6}$ for $500 \mathrm{~kg}$ of uranium entering the plant in the yellowcake). 
Table 1. Suggested key measurement points

\begin{tabular}{|c|c|c|}
\hline $\begin{array}{l}\text { Key } \\
\text { measurement } \\
\text { point number }\end{array}$ & Location & Justification \\
\hline 1 & $\begin{array}{l}\text { Quantity of yellowcake } \\
\text { received at the NUCP for } \\
\text { processing }\end{array}$ & $\begin{array}{l}\text { This is a record of the uranium entering the plant. The } \\
\text { uranium amounts entering and exiting the NUCP, as feed } \\
\text { and product, respectively, are the minimum required key } \\
\text { measurement points. }\end{array}$ \\
\hline 2 & $\begin{array}{l}\text { Yellowcake fed from the feed } \\
\text { hopper to the dissolver }\end{array}$ & $\begin{array}{l}\text { This gives an independent verification of the quantity of } \\
\text { yellowcake entering the process and helps prevent } \\
\text { introducing "unaccounted" material that can be diverted } \\
\text { before the first key measurement point downstream of the } \\
\text { dissolver. This gives the input value for mass balance } \\
\text { analysis. }\end{array}$ \\
\hline 3 & $\begin{array}{l}\text { UN solution exiting the UN } \\
\text { tank downstream of the } \\
\text { dissolver }\end{array}$ & $\begin{array}{l}\text { This gives the first analysis of the uranium dissolved } \\
\text { from the yellowcake and helps prevent diversion of } \\
\text { dissolved uranium or use of the equipment to process } \\
\text { unaccounted uranium. The uranium in solution should } \\
\text { match the uranium coming in with the yellowcake, minus } \\
\text { what exited with the undissolved solids. }\end{array}$ \\
\hline 4 & $\begin{array}{l}\text { Purified aqueous UN solution } \\
\text { exiting the strip column after } \\
\text { solvent extraction purification }\end{array}$ & $\begin{array}{l}\text { This provides a mass balance check after purification of } \\
\text { the uranium, an attractive point of diversion. }\end{array}$ \\
\hline 5 & $\begin{array}{l}\text { "Stripped" organic stream } \\
\text { exiting the strip column for } \\
\text { solvent extraction purification }\end{array}$ & $\begin{array}{l}\text { This helps prevent inefficient stripping and possible } \\
\text { diversion of uranium away from the main uranium path } \\
\text { through solvent recycle/disposal. }\end{array}$ \\
\hline $6 a$ or $b$ & $\begin{array}{l}\text { Aqueous UN solution exiting } \\
\text { the evaporator; monitors either } \\
\text { (a) in the line exiting evaporator } \\
\text { before passing through any } \\
\text { valves or equipment or (b) just } \\
\text { before the cooler leading to the } \\
\text { storage tank }\end{array}$ & $\begin{array}{l}\text { The evaporator provides another opportunity for } \\
\text { diversion after purification. Measuring here helps prevent } \\
\text { that. Each intervening valve or piece of equipment } \\
\text { provides another opportunity for diversion. Hence, } \\
\text { arguments can be made to monitor right out of the } \\
\text { evaporator or just downstream of the reflux leg back into } \\
\text { the evaporator and ahead of the cooler leading into the } \\
\text { storage tank. }\end{array}$ \\
\hline 7 & $\begin{array}{l}\text { Dry uranium solid (AUC) after } \\
\text { precipitation }\end{array}$ & $\begin{array}{l}\text { This is right after the uranium has been solidified and } \\
\text { collected. Measuring here verifies the uranium dissolved } \\
\text { and purified and helps prevent diversion during } \\
\text { precipitation/denitration. Some NUCPs collect the } \\
\text { product in drums at this point for transport to the next } \\
\text { step in the process. If so, this could be a traditional } \\
\text { accountability system using a surveillance system for } \\
\text { drum counting and nondestructive analysis to estimate } \\
\text { uranium per drum. }\end{array}$ \\
\hline 8 & $\begin{array}{l}\text { Uranium hexafluoride collected } \\
\text { in cylinders for shipping }\end{array}$ & $\begin{array}{l}\text { This gives the product output value for mass balance } \\
\text { analysis. The uranium in this product combined with the } \\
\text { uranium in the waste streams should match the input } \\
\text { uranium value. The uranium amounts entering and } \\
\text { exiting the NUCP, as feed and product, respectively, are } \\
\text { the minimum required key measurement points. }\end{array}$ \\
\hline
\end{tabular}


Diversion can occur in nearly an infinite number of ways within a finite NUCP. The key measurement points will not only be finite, but also probably minimal. The logical strategic points reviewed above give a reasonable number of finite points to consider for a measurement program. To generate an overall mass balance for an NUCP, the uranium entering and leaving the plant as the yellowcake feed and $\mathrm{UF}_{6}$ product must be measured. In addition to these two points, at least one internal key measurement point is recommended, for a total of at least three key measurement points. If only one internal key measurement point is used, the recommended point is just after purification (where the aqueous material exits the strip column). Diversion is not attractive until after purification, and the point at which this happens is the logical place to measure for comparison with the feed and product uranium mass rates.

Table 2 summarizes safeguards approaches that can be used at the suggested key measurement points. The steps required to implement a safeguards system include the following:

a. proof of principle,

b. selection of specific systems,

c. procurement of hardware,

d. lab-scale testing,

e. final procedure development,

f. full-scale demonstration, and

g. final deployment.

Table 2. Safeguards for the suggested key measurement points from Table 1

\begin{tabular}{|c|c|c|c|}
\hline $\begin{array}{c}\text { Key } \\
\text { measurement } \\
\text { point number }\end{array}$ & Process parameters & Safeguards system & $\begin{array}{c}\text { Steps required to } \\
\text { implement } \\
\text { safeguards } \\
\text { system }\end{array}$ \\
\hline \multirow[t]{2}{*}{1} & \multirow{2}{*}{$\begin{array}{l}\text { Solid yellowcake received } \\
\text { in drums, stored, and } \\
\text { dumped into feed hopper } \\
\text { for dissolver }\end{array}$} & Accounting with grab samples taken for DA & $\mathrm{g}$ \\
\hline & & Nondestructive analysis of uranium in drum & $\mathrm{a}$ \\
\hline 2 & $\begin{array}{l}\text { Solid yellowcake fed } \\
\text { from bottom of feed } \\
\text { hopper to the dissolver }\end{array}$ & $\begin{array}{l}\text { Mass rate of solid feed using process } \\
\text { gravimetric techniques combined with } \\
\text { analysis of uranium content from } \\
\text { measurement point } 1 \text { or DA of grab samples } \\
\text { from measurement point } 2\end{array}$ & b-g \\
\hline 3 & Unpurified UN solution & $\begin{array}{l}\text { In-line measurement of uranium } \\
\text { concentration, } \mathrm{pH} \text {, density, conductivity, } \\
\text { temperature, and flow rate }\end{array}$ & b-g \\
\hline 4 & Purified UN solution & $\begin{array}{l}\text { In-line measurement of uranium } \\
\text { concentration, pH, density, conductivity, } \\
\text { temperature, and flow rate }\end{array}$ & b-g \\
\hline 5 & Stripped organic liquid & $\begin{array}{l}\text { In-line measurement of uranium } \\
\text { concentration, density, temperature, and } \\
\text { flow rate }\end{array}$ & b-g \\
\hline 6 & $\begin{array}{l}\text { Concentrated purified UN } \\
\text { solution }\end{array}$ & $\begin{array}{l}\text { In-line measurement of uranium } \\
\text { concentration, } \mathrm{pH} \text {, density, conductivity, } \\
\text { temperature, and flow rate }\end{array}$ & b-g \\
\hline 7 & $\begin{array}{l}\text { Purified solid dry uranium } \\
\left(\mathrm{AUC} \text { or } \mathrm{UO}_{3} \text { ) }\right.\end{array}$ & Accounting with grab samples taken for DA & g \\
\hline 8 & $\begin{array}{l}\text { Uranium hexafluoride } \\
\text { collected and stored in } \\
\text { cylinders }\end{array}$ & Accounting with grab samples taken for DA & g \\
\hline
\end{tabular}




\section{DETECTION TECHNIQUES AND TECHNOLOGIES}

By analyzing the generic natural uranium conversion process, the attractive diversion routes for intermediate products within the process can be ascertained. Out-of-specification $\mathrm{UF}_{6}$ produced in the fluorination process could be reduced back to $\mathrm{UF}_{4}$, followed by metallothermic reduction into uranium metal that could be used in the AVLIS enrichment process or in plutonium production. By the same token, $\mathrm{UF}_{4}$ produced in the hydrofluorination process could be metallothermically reduced to uranium to be used in the AVLIS enrichment process or in plutonium production. Also, $\mathrm{UF}_{6}$ could be used for a GCEP or GDEP. The analysis of diversion scenarios not only includes these possible scenarios, but also considers other options such as material substitution where higher-uranium-concentration material can be substituted for lower-uranium-concentration material; equipment can suffer alterations, such as scales for weighing containers; or operations can be modified, such as raffinate uranium concentration. Data tampering is also considered in the diversion scenario. In essence, every stage in the generic natural conversion process is closely observed for possibilities of diversion. Based on this analysis a desired number of strategic points are determined. These strategic points are mainly driven by mass balance principles. Consequently, the key measurement points should be supported by instrumentation that can verify mass balances. Flow meters, to measure flow of material, and instruments that measure the concentration of uranium are ultimately required for this analysis. This report includes a pros-and-cons analysis of each instrument, reliability analysis, maturity, and maintainability.

\subsection{MASS BALANCE}

A mass balance for this plant operation has to be proposed and recorded.

\subsection{ACCOUNTING}

Mass balance performed at different sections of the uranium conversion process will indicate possible diversions. The main source of material will come from the declared values of the material.

\subsection{VERIFICATION ACTIVITIES}

The accounting methodology for reviewing the declared values will have to be confronted with some verification procedures. Nondestructive analysis (NDA) using germanium or sodium iodide detectors may not provide checking information for the mass balance because of the self-shielding properties of uranium. A passive neutron technique for measuring the bulk uranium concentration in the drums is recommended. However, the technology requires development, and the equipment necessary for the analysis can be rather expensive. 


\subsection{EQUIPMENT CONFIGURATION}

\subsubsection{Waste Stream Analysis}

The process for the conversion of yellowcake into $\mathrm{UF}_{6}$ is well established. However, the operation mode depends a great deal on local work schedules. These schedules will determine the flow rates at every point of interest within the plant. Two operation modes have been assumed that will limit the flow rates within the plant. Option 1 is defined as having a working schedule of $24 \mathrm{~h} / \mathrm{d}$ for $180 \mathrm{~d} /$ year. Option 2 is defined as having a working schedule of $24 \mathrm{~h} / \mathrm{d}$ for $90 \mathrm{~d} /$ year. These two operation modes will indicate a range of flow rates for the key measurement points with their respective uranium concentrations.

\subsubsection{Needed Precision of Analytical Technique}

Tables 3 and 4 indicate the flow rates and uranium concentrations at the defined key measurement points. To estimate the needed precision for the instrumentation required to control these strategic points, it is necessary to establish a basic scenario with a diversion quantity for which this controlling system is appropriate. Tables 3 and 4 indicate the concentration of uranium in specific streams of interest for both continuous operations $24 \mathrm{~h} / \mathrm{d}$ for $90 \mathrm{~d}$ and $24 \mathrm{~h} / \mathrm{d}$ for $180 \mathrm{~d}$.

Table 3. Flow rates and concentration at key measurement points $D, F$, and $L^{*}$

\begin{tabular}{|l|c|c|c|c|c|c|}
\hline \multirow{2}{*}{} & \multicolumn{2}{|c|}{$\begin{array}{c}\text { After vacuum filter } \\
\text { (D) }\end{array}$} & \multicolumn{2}{c|}{$\begin{array}{c}\text { Before extraction } \\
\text { (F) }\end{array}$} & \multicolumn{2}{c|}{$\begin{array}{c}\text { After stripping } \\
\text { (L) }\end{array}$} \\
\cline { 2 - 7 } & $\mathbf{9 0 ~ d , ~ 2 4 ~ h / d ~}$ & $\mathbf{1 8 0 ~ d , ~ 2 4 ~ h / d ~}$ & $\mathbf{9 0 ~ d , ~ 2 4 ~ h / d ~}$ & $\mathbf{1 8 0 ~ d , ~ 2 4 ~ h / d ~}$ & $\mathbf{9 0 ~ d , ~ 2 4 ~ h / d ~}$ & $\mathbf{1 8 0 ~ d , ~ 2 4 ~ h / d ~}$ \\
\hline Liter/hour & 660 & 330 & 640 & 320 & 2,840 & 1,420 \\
\hline Grams uranium/hour & 231,000 & 115,500 & 224,000 & 112,000 & 227,200 & 113,600 \\
\hline Grams uranium/liter & 350 & 350 & 350 & 350 & 80 & 80 \\
\hline
\end{tabular}

* Letter refers to stream as shown in Fig. 5.

Table 4. Flow rates and concentration at monitoring points $\mathrm{M}, \mathrm{N}$, and $\mathrm{O}^{*}$

\begin{tabular}{|l|c|c|c|c|c|c|}
\hline & \multicolumn{2}{|c|}{$\begin{array}{c}\text { Organic waste from } \\
\text { stripping } \\
\text { (M) }\end{array}$} & $\begin{array}{c}\text { Concentrated solution from } \\
\text { the evaporator } \\
\text { (N) }\end{array}$ & \multicolumn{2}{c|}{$\begin{array}{c}\text { Condensate from the } \\
\text { evaporator } \\
\text { (O) }\end{array}$} \\
\cline { 2 - 7 } & $\mathbf{9 0 ~ d , ~ 2 4 ~ h / d ~}$ & $\mathbf{1 8 0 ~ d , ~ 2 4 ~ h / d ~}$ & $\mathbf{9 0 ~ d , ~ 2 4 ~ h / d ~}$ & $\mathbf{1 8 0 ~ d , ~ 2 4 ~ h / d ~}$ & $\mathbf{9 0 ~ d , ~ 2 4 ~ h / d ~}$ & $\mathbf{1 8 0 ~ d , ~ 2 4 ~ h / d ~}$ \\
\hline Liters/hour & 26,800 & 13,400 & 640 & 320 & 1,100 & 550 \\
\hline Grams uranium/hour & 8,040 & 4,020 & 224,000 & 112,000 & 2.2 & 1.1 \\
\hline Grams uranium/liter & 0.3 & 0.3 & 350 & 350 & 0.002 & 0.002 \\
\hline
\end{tabular}

* Letter refers to stream as shown in Fig. 5.

\subsection{REVIEW OF AVAILABLE TECHNOLOGIES FOR PROCESS MONITORING}

Quite a few tools can be used to measure the concentration of uranium in solutions as well as in solid form. Flow rates need to be considered as part of the data requirement if generalized uranium mass balances are going to be part of a study. The first step is analyzing photometric techniques to determine the concentration of uranium in solutions.

Process stream monitoring requires, at the basic level, measurement of flow and composition at each location of interest. These parameters can be measured by a variety of direct and indirect methods. 
Because the form of the process material varies greatly between the several key measurement points of interest, combinations of methods will be needed to monitor all locations.

A brief review was conducted of potentially useful instrumentation. Methods that appear to be capable of determining flow or composition (directly or indirectly) were sought. Special attention was given to the degree of process intrusiveness, features that would indicate long-term stability (e.g., no moving parts), and the ability of the instrument signal to be remotely monitored. Nonintrusive technologies are those that do not require inserting components into the process stream but rather mount outside a process pipe or conveyor. From a facility standpoint (and possibly also a reliability standpoint), relatively nonintrusive methods are likely to be favored if they can achieve the desired accuracy and reliability.

This review sought commercially available process-scale industrial instrumentation. Results of this brief review indicate that process monitoring of all the proposed in-plant key measurement points considered (points 2 through 7) can probably be handled by commercially available instrumentation, and much of that instrumentation can be nonintrusive. However, the actual applicability, long-term reliability, resistance to tampering, interferences, and limitations will have to be determined by testing the instrumentation under controlled conditions over prolonged periods.

\subsubsection{Liquid Flow}

Mass or volume flow measurement in liquids can be made by a variety of techniques with differing degrees of intrusiveness, discrimination, and accuracy.

Intrusive process flow meters are readily available. Common types operate on pressure drop (e.g., the Yokogawa EJA series differential pressure liquid flow meter and density units) and are likely to be highly stable and reliable. Vortex flow meters mount in-line and would be perceived as less disruptive of the process. Suppliers of vortex flow meters include Dynasonics, EMCO, and Sparling. The Coriolis flow measuring system is a type of instrument that simultaneously measures mass, density, temperature, and viscosity. Volume flow, density, and temperature (the primary measured variables) can be used to derive other variables such as mass flow, solid contents, concentrations, and density functions. The measuring system consists of a transmitter and a sensor. Two versions are available: (1) a compact version in which the transmitter and sensor form a single measuring unit and (2) a remote version in which the transmitter and sensor are installed separately. Figure 8 shows one of the Coriolis flow measuring instruments. Endress+Hauser produces this instrument in Germany.

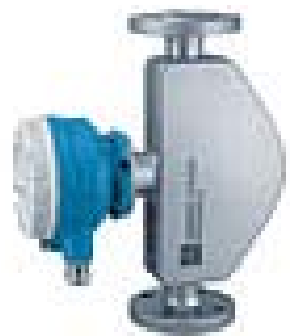

Fig. 8. Example of a Coriolis flow measuring system.

Nonintrusive models that are commercially available generally operate on acoustic principles. Ultrasonic process liquid flow-measurement instruments are readily available commercially. Some operate on Doppler shift (the fluid requires a low level of particulate or bubbles); others measure upstream/downstream transit time differences.

One supplier of such instruments reviewed for this activity is GE Panametrics. This firm offers several models of differential transit time units capable of monitoring flow of a wide variety of liquids.

Panametrics instruments operate on transit time changes. Sound source and detector components can be either wetted (transducers mounted in the process fluid) or clamped on (sensors mounted on the exterior of the pipe).

Better accuracy is expected for the intrusive configuration, but reasonable accuracy (2\% of flow) is claimed for the nonintrusive configuration. GE Panametrics is only one of several suppliers of similar instrumentation. Controlotron, a U.S. company, produces a permanent clamp-on multifunction ultrasonic flow meter. The system is a nonintrusive, permanent flow meter that provides 
measurements of liquid flow over wide flow ranges and liquid types. It is capable of measuring volumetric, mass, and thermal energy flow. The clamp-on method of transducer installation provides many advantages, including easy installation, no pipe cutting, low maintenance, and no pressure drop. Other companies producing such instruments include Dynasonics and EMCO.

\subsubsection{Solid Flow}

Solid flow is generally measured by in-line (i.e., intrusive) mechanical systems, which may operate on several principles (e.g., momentum transfer, Coriolis principle, weight). Some manufacturers of such devices are S-E-G Instrument, Schenk-AccuRate, and Enexco.

One nonintrusive solid-flow monitoring device was located. This unit, offered by Berthold, operates by gamma transmission through the solids-conveying process component (e.g., conveyor belt, screw-conveyor).

\subsubsection{Composition}

Composition can be deduced by a variety of methods. In all cases some degree of process knowledge is needed (i.e., there needs to be an expected range of composition). Some of the properties that could be used to infer composition are density, spectroscopic methods, or (for uranium) radiation.

\subsubsection{Density}

Many devices are commercially available that are capable of determining liquid density. Most of these are process intrusive. Many operate on the principle of measuring the (acoustic) resonant frequency of a vibrator in the presence of the liquid of variable density. Companies offering such devices include Anton Paar, Chandler Engineering, Solartron, Dynatrol, Princo Instruments, and Calibron.

One nonintrusive (i.e., clamp-on) acoustic density monitor was found, offered by HiTECH Technologies. It is reported that it can measure fluid density to a fraction of a percent in aqueous solutions or petroleum distillates.

Other nonintrusive density measurement devices operate on the principle of attenuation of an X-ray or gamma beam. Berthold Technologies and Ronan Engineering Company both offer such units.

Through-pipe units are offered by both companies, and through-conveyor versions are offered by Berthold. Measurements should reasonably correspond to density of the material in the gamma beam, but they would need to be calibrated to the expected composition of the material being measured.

\subsubsection{Spectroscopic Methods}

A more direct measure of composition of a solution can be obtained using spectroscopic methods. One manufacturer of commercial fiber-optic probes capable of carrying out near-infrared or ultraviolet/visible spectroscopy is Hellma. Some of its probes are intended for industrial process monitoring. They would need to be inserted into the fluid stream. If the range of compositions is reasonably well known, automated spectroscopic interpretation could readily be done.

The optical path length through the process fluid would need to be tailored to the expected range of compositions, and there might be a lower limit on the practical path length, which could preclude its use in extremely concentrated solutions. These probes can be interfaced to PC-based plug-in spectrometers, such as the ones offered by Ocean Optics. 
Nonintrusive composition measurement will be more difficult to attain. Gamma spectroscopy methods could qualitatively determine the presence of uranium, but accurate determination of the quantity could be difficult.

\subsubsection{Tabulated Summary}

Tables 5 and 6 show the likely applicability of the various categories of methods to the internal monitoring points shown in Fig. 7.

Table 5. Flow measurement methods-applicability to key measurement points

\begin{tabular}{|l|c|c|c|c|c|c|c|}
\hline \multicolumn{1}{|c|}{ Monitoring point } & Intrusive? & $\mathbf{2}$ & $\mathbf{3}$ & $\mathbf{4}$ & $\mathbf{5}$ & $\mathbf{6}$ & $\mathbf{7}$ \\
\hline Acoustic/clamp-on & No & & $\mathrm{x}$ & $\mathrm{x}$ & $\mathrm{x}$ & $\mathrm{x}$ & \\
\hline Acoustic/in-process & Yes & & $\mathrm{x}$ & $\mathrm{x}$ & $\mathrm{x}$ & $?$ & \\
\hline Conventional flanged orifice & Yes & & $\mathrm{x}$ & $\mathrm{x}$ & $\mathrm{x}$ & $?$ & \\
\hline Vortex & Yes & & $\mathrm{x}$ & $\mathrm{x}$ & $\mathrm{x}$ & $?$ & \\
\hline Radiometric solid mass flow & No & $\mathrm{x}$ & & & & & $\mathrm{x}$ \\
\hline Conventional solid mass flow & Yes & $\mathrm{x}$ & & & & & $\mathrm{x}$ \\
\hline
\end{tabular}

$\mathrm{x}=$ appears to be applicable

? = of questionable or limited applicability

Table 6. Composition measurement methods-applicability to key measurement points

\begin{tabular}{|l|c|c|c|c|c|c|c|}
\hline \multicolumn{1}{|c|}{ Monitoring point } & Intrusive? & $\mathbf{2}$ & $\mathbf{3}$ & $\mathbf{4}$ & $\mathbf{5}$ & $\mathbf{6}$ & $\mathbf{7}$ \\
\hline Acoustic/clamp-on & No & & $\mathrm{x}$ & $\mathrm{x}$ & $\mathrm{x}$ & $?$ & \\
\hline Acoustic/in-process & Yes & & $\mathrm{X}$ & $\mathrm{X}$ & $?$ & $?$ & \\
\hline Photometric & Yes & & $\mathrm{X}$ & $\mathrm{X}$ & $?$ & $\mathrm{X}$ & \\
\hline Gamma transmission & $\mathrm{No}$ & $\mathrm{X}$ & $\mathrm{X}$ & $\mathrm{X}$ & $?$ & $\mathrm{X}$ & $\mathrm{X}$ \\
\hline Radiation monitoring & No & $?$ & $?$ & $?$ & & $?$ & $?$ \\
\hline
\end{tabular}

$\mathrm{x}=$ appears to be applicable

$?=$ of questionable or limited applicability

The following is a list of the web pages of manufacturers mentioned in this report:

www.calibron.com, www.chandlerengineering.com, www.controlotron.com, www.dynasonics.com, www.dynatrolusa.com, www.emcoflow.com, www.enexco.com, www.gepower.com/prod_serv/products/flowmeters/en/index.htm (GE-Panametrics), www.hellma-worldwide.de, 
www.hitech.com, www.princoinstruments.com, www.ronanmeasure.com, www.sparlinginstruments.com, www.us.yokogawa.com, and www.oceanoptics.com.

\subsection{DETERMINATION OF URANIUM CONCENTRATION IN AQUEOUS NITRIC ACID SOLUTIONS FROM TEMPERATURE, CONDUCTIVITY, AND DENSITY MEASUREMENTS}

In the current state of development, conductivity and density are dependent variables; temperature and concentration are independent variables. Because of the mathematical configuration of the algorithms, direct inversion to make the concentration dependent on conductivity, temperature, and density is not possible. Consequently, determination of the concentration based on the measurement of the other variables is iterative.

The algorithms for uranium concentration in aqueous nitric acid are accurate to within $3 \%$ in their current forms, and they are applicable to nitric acid concentrations ranging from 2 to $6 \mathrm{M}$, uranium concentrations ranging from 160 to $300 \mathrm{~g} / \mathrm{L}$, and temperatures ranging from 25 to $95^{\circ} \mathrm{C}$.

The primary means for increasing the precision of uranium concentration determination from the remaining variables is to expand the algorithms to include higher-order terms, thereby increasing the accuracy of the prediction algorithms. Computer processing speed and memory capabilities at the time the algorithms were developed were significantly less than those currently available using commercial personal computers. Therefore, it is expected that significant precision improvements could be made relatively easily without adversely affecting the response time of the system.

\subsection{NONDESTRUCTIVE ASSAY FOR ANALYSIS OF URANIUM CONCENTRATION FOR BULK SOLIDS}

The accounting methodology of reviewing the declared values will have to be confirmed by some verification technique(s). Low-energy, gamma-ray interrogation, passive neutron coincidence counting, and active neutron coincidence counting are NDA techniques that measure the quantity of uranium, uranium isotope, or uranium decay daughter. These techniques are routinely used for mass balance verification during processing of enriched uranium or plutonium or to identify and quantify small amounts found in sealed waste packages (e.g., drums).

The most significant shortcoming of the gamma-ray interrogation system for this application is the lack of penetration of the gamma rays through the dense, high-Z matrix. Using appropriate assumptions, measurement of the $186 \mathrm{keV}$ characteristic line from ${ }^{235} \mathrm{U}$ results in the interrogation of less than the outermost $2.5 \mathrm{~cm}$ of the drum. Even using the more penetrating $1001 \mathrm{keV}$ line for protactinium-233, daughter of ${ }^{238} \mathrm{U}$, only the outermost $10 \mathrm{~cm}$ of the drum can be effectively verified, meaning that the gamma analysis "sees" only about half the material in the drum.

A common method for assaying uranium materials is the active well coincidence counter. The shuffler relies on the use of a californium-252 source to induce fission within the sample, and then delayed neutrons are counted. The differential die-away (DDA) system uses a $14 \mathrm{MeV}$ pulsed neutron source but requires that the neutrons be moderated to thermal energies as part of the detection technique. The thermalized neutrons induce fission, and the fission neutrons are counted directly. The shuffler and 
DDA system are affected by the presence of moderating materials (e.g., water). Both systems are costly and more complicated than equipment needed for taking passive measurements, and neither system is considered to be suited for taking this measurement.

The passive neutron coincidence counting approach takes advantage of the spontaneous fission of ${ }^{238} U$ to provide a penetrating assay of the uranium oxide drum. The results for relatively dry samples are very encouraging and readily provide an expected accuracy of only a few percent in less than $1 \mathrm{~h}$ counting time. However, adding moisture significantly affects the assay, and the resulting measurements may not be correctable- that is, adding water to the drums may conceal uranium from this NDA. The assay is also affected by the uranium bulk density, but this effect appears correctable.

\subsection{URANIUM FLOW AND CONCENTRATION MONITORING, DEVELOPMENT, AND DEMONSTRATION OF IN-LINE INSTRUMENTATION IN NATURAL URANIUM CONVERSION FACILITIES}

In response to IAEA interests, ORNL and Los Alamos National Laboratory (LANL) formed a collaborative effort to address and develop safeguards for uranium that can be applied earlier in the fuel cycle than has been the customary practice. This collaboration is part of a DOE-sponsored project, performed under a U.S./ United Kingdom agreement. The main objective was to demonstrate technology for uranium flow measurement in an NUCP.

This work included researching and selecting several commercially available flow meters ${ }^{4}$ for small-scale laboratory testing. After investigating approximately 50 flow meters, the following were selected:

- Endress + Hauser ProMass 83F Coriolis Flow Meter-Selected because of its ability to measure density as well as flow rates with excellent accuracy and repeatability. More information is available at www.endress.com.

- Yokogawa ADMAG SE Magnetic Flow Meter-Selected because of the level of accuracy and its ability to measure low flow rates. More information is available at www.yokogawa.com/us.

- Controlotron 1010N1 Transit-Time Ultrasonic Flow Meter-Selected because of the nonintrusive nature of the instrument. More information is available at www.controlotron.com.

The ORNL team then had to design and build a UN flow loop (shown in Fig. 9) for evaluating uranium flow meter hardware. The meters' responses to various flow rates, entrained air, pulsating flow, and entrained organic (1-5 vol \% kerosene) were tested. LANL developed a neutron detector and a data acquisition instrumentation system for the entire system. The initial task was completed with the recommendation that the Coriolis flow meter be used for testing at a production-scale facility. The setup for the subsequent production-scale demonstration at a Springfield, Tennessee, facility is shown in Fig.10.

\footnotetext{
${ }^{4}$ J.L. Ladd-Lively, "Safeguards Application of Flowmeters in Natural Uranium Conversion Plants," presented at the INMM 47th Annual Meeting, Nashville, Tennessee, 2006.
} 


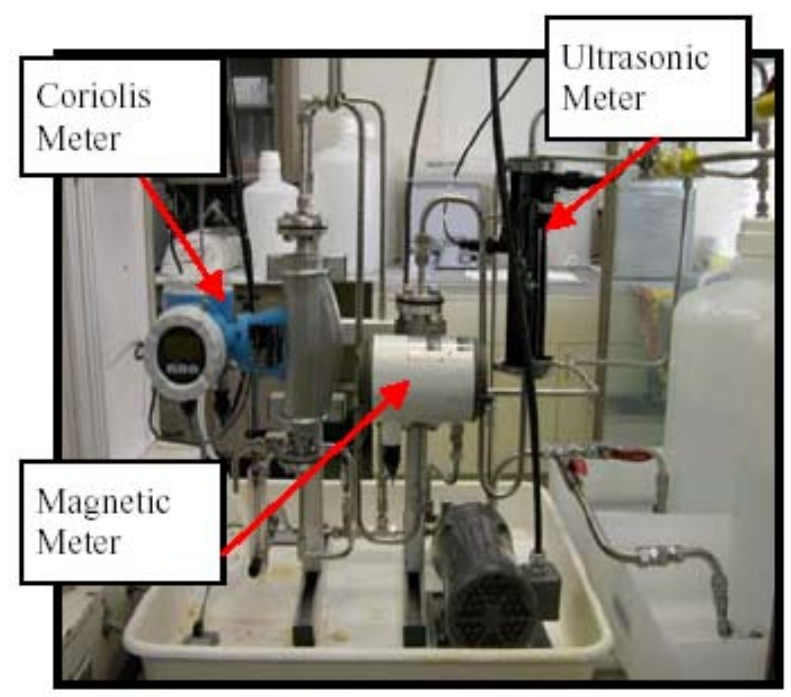

Fig 9. Uranyl nitrate flow loop.

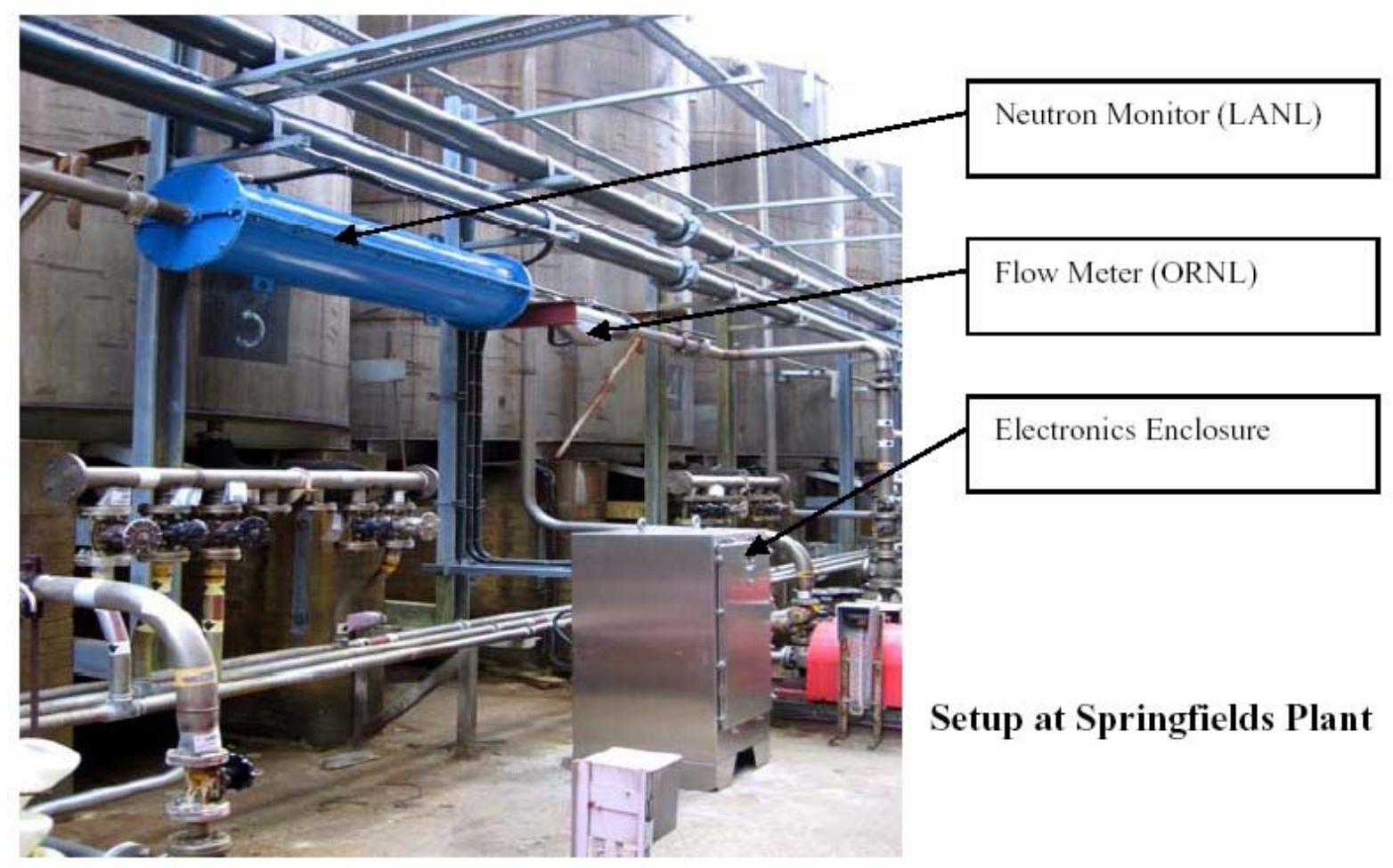

Fig. 10. Setup of the flow loop at the Springfield facility.

\section{RESULTS OF JOINT EXPERIMENTS WITH FLOW METERS AND GAMMA-RAY DETECTORS}

The flow loop system and new gamma-ray detection systems were demonstrated to members of CNEN. The remainder of this section is a summary of the activities performed during the one-week visit to ORNL by a Brazilian delegation. 


\subsection{COMMENTS ON FLOW METERS}

Continuous monitoring of uranium solution process streams is frequently considered as a potential technique to support safeguards implementation in a natural uranium conversion plant and Brazil is interested in observing and evaluating the performance of these instruments. This demonstration consisted in the following activities:

- Overview and tour

- Various flow rates

- Response to start/stop of pump

- Various flow rates with organics

- Air entrainment in the system

- Remote monitoring of the system

Two tested instruments (Endress+Hauser Promass 83F Coriolis meter and Yokogawa ADMAG SE Magnetic flow meter) require interruption of the line for physical contact with the solution being monitored. Another tested flow meter based on ultrasonic emission can perform the task by wrapping the instrument to a pipe, making it easier to be installed and maintained. However, due to operating principles, the Coriolis and the magnetic models usually perform better than the ultrasonic meter.

The test loop has the capability to test the flow meters' responses to various flow rates (0-16 LPM), entrained air, and pulsating flow conditions. As well as, tests with entrained organic (1-5 vol\% kerosene) in the UN solution.

LabView is used for the data acquisition system. The DAQ computer can be remotely monitored. Two web cameras were mounted inside the hood to monitor for proper operation of the system. The cameras can also be viewed remotely. Additional cameras could be mounted outside the hood or the current cameras could be moved to a different location.

The system includes 2 tanks for feed material, which can be changed with a valve. This currently allows for the organic solution to remain separate from the pure solution. The organic tank is currently empty and could be used to simulate a diversion of material. All the valves in the system are manually operated.

The selection of the most adequate instrumentation is usually based on several boundary conditions, including facility operational restrictions and intrusiveness limitations. As usual, in safeguards applications, prior to final qualification any instrumentation has to be exhaustively tested to ensure appropriate reliability and performance levels, under different measurement conditions. In this context, two evaluation steps are usually considered. First, the development of a test loop capable to simulate various measurement conditions and, secondly, provide sufficient performance information to be used as input data for guiding posterior tests in a real plant.

In addition, other safeguards related technical aspects have to be taken into account: data authentication, tampering indication, calibration requirements, user interface, data evaluation, and installation concerns.

The monitoring of nuclear materials in the plant usually requires the use of radiation detection techniques. Since commercial flow meters do not perform radiation measurement, the use of such instrumentation as a safeguards tool has to be associated with additional detection systems.

Preliminary tests using neutron detectors indicate that this measurement technique may be used to quantify relative uranium isotopes densities present in the stream. However, the most adequate calibration methodology for such a detection systems is still under evaluation. 
Figures 11 and 12 show the results of water calibrations and comparisons of Coriolis and magnetic flow meters, respectively.

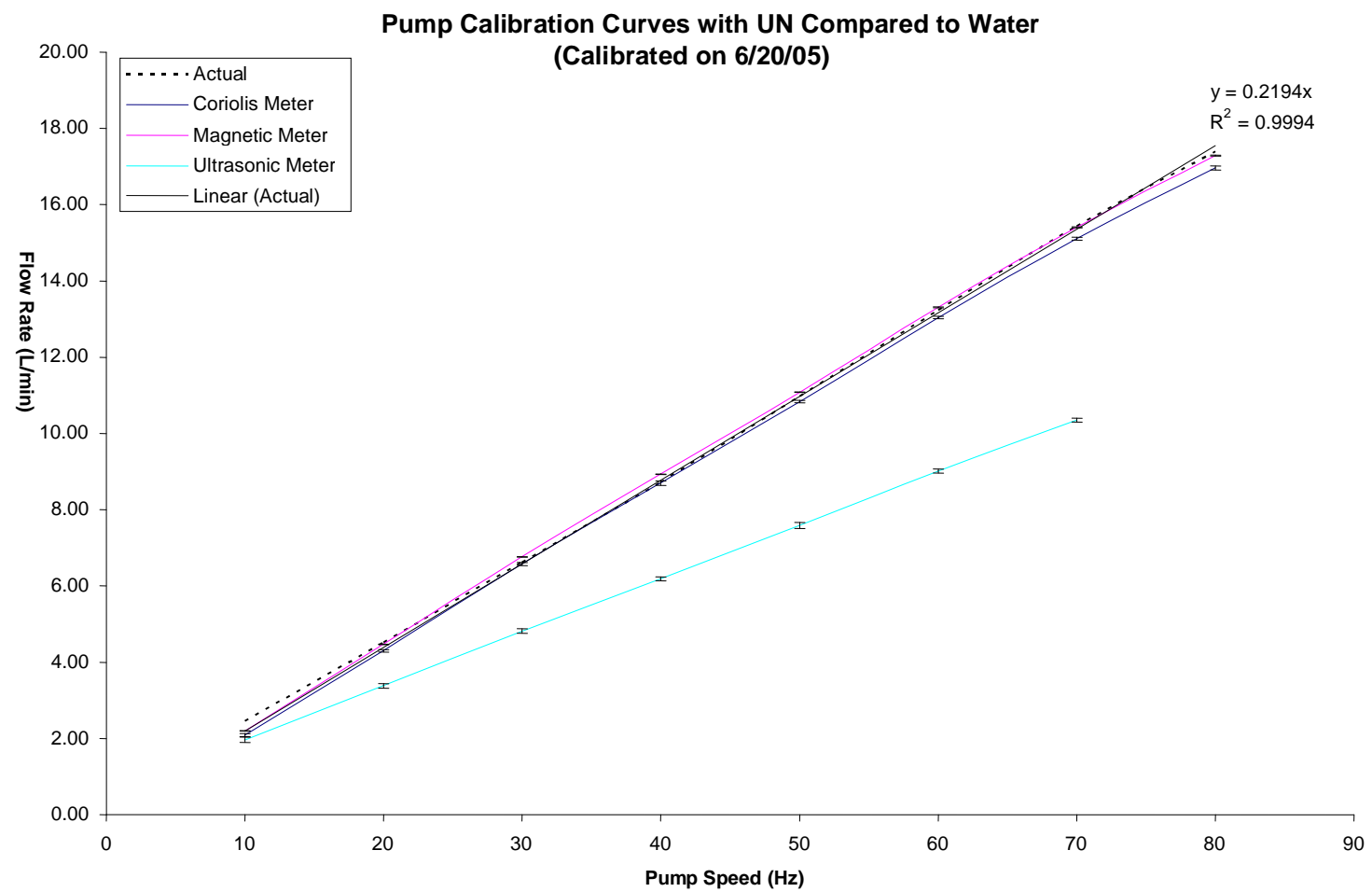

Fig. 11 Water calibrations.

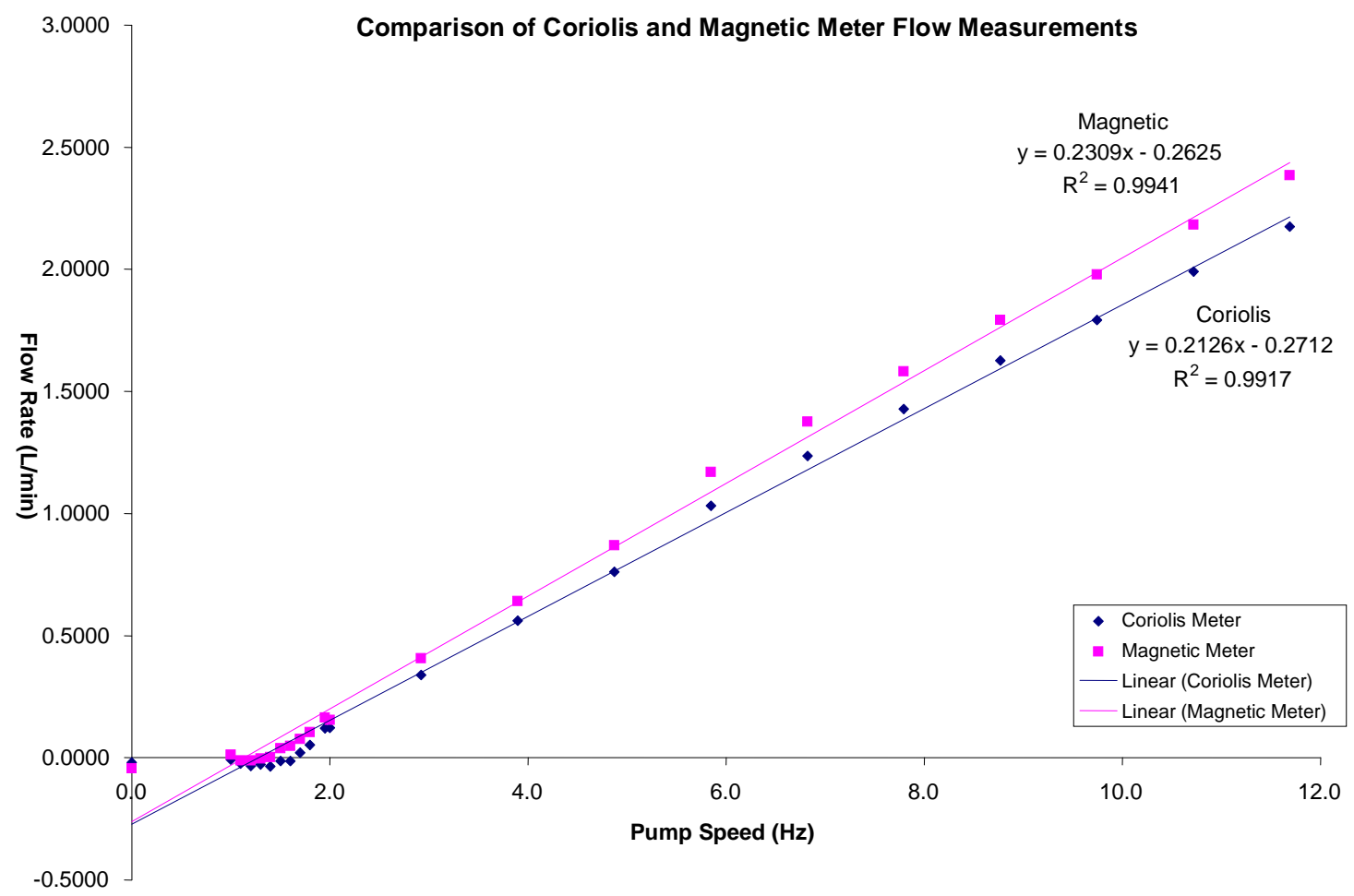

Fig. 12. Comparison of Coriolis and magnetic flow measurements. 


\subsection{COMMENTS ON GAMMA-RAY DETECTORS}

Gamma-ray spectroscopy is a widely used measurement technique. Measurements often need to be performed in the field, during inspections at nuclear facilities, as a way to promptly draw safeguards conclusions. In this context, the use of portable instrumentation, such as radiation detectors and pulse analysis modules, play an important role.

There are several commercially available gamma-ray detection systems. In order to select the most adequate detection system for a certain application, two performance parameters are usually important: energy resolution and detection efficiency.

High-purity germanium (HPGe) detectors represent the current state-of-the-art in terms of energy resolution. Therefore, such detectors are commonly used for quantitative measurements that require improved performance. HPGe detectors have to operate under extremely low temperatures and use liquid nitrogen to cool down the crystal. For field applications, this requirement may represent a problem if liquid nitrogen cannot be easily obtained.

Recent technological developments on radiation detection have provided to the nuclear community interesting options for field applications. New techniques to cool down HPGe crystals have been developed based on electrical or mechanical systems. This is the case of two recently developed portable systems: the Detective, manufactured by AMETEK/ORTEC, and the Falcon, manufactured by CANBERRA.

Preliminary evaluations of both systems have shown they may constitute an attractive measurement tool for nuclear material accountancy. In addition to the attractive feature of not requiring liquid nitrogen, the new cooling technologies may significantly decrease the time delay required to start a cooling cycle after the detector has warmed up to room temperature. While conventional liquid nitrogen cooled HPGe detectors require many hours, the new systems may require only a few minutes.

Taking into account safeguards applications, some disadvantages have been identified. First, since no specific analysis tool for safeguards is integrated to any of the currently available equipment, it is necessary to extract the collected spectra and analyze them with additional software installed on a computer. Second, the high cost may reduce the number of potential users that could be interested in improving their measurement procedures and conducting performance tests, contributing to a consistent assessment of these new technologies.

Still in the field of gamma-ray spectroscopy, other important development has to be mentioned: scintillation detectors based on lanthanum bromide $\left(\mathrm{LaBr}_{3}\right)$ crystals ${ }^{8}$. The most attractive features of such detector type include the improved energy resolution and total efficiency compared with traditional $\mathrm{NaI}(\mathrm{Tl})$ crystals. The operation at room temperature with good stability is also an important advantage.

Preliminary tests indicate significant improvement for quantitative determination of uranium. However, a more consistent performance evaluation, under different measurement conditions, has to be performed. In addition, modern gamma-ray analysis codes based on peak fitting algorithms are not prepared for evaluating typical $\mathrm{LaBr}_{3}$ spectra. Considering these codes are widely and frequently used by the safeguards community as an important gamma-ray analysis tool, a more realistic assessment of $\mathrm{LaBr}_{3}$ performance will be possible only after modified code versions have been developed. 


\section{CONCLUSION}

\subsection{FLOW METERS}

Additional tests are necessary for the following reasons:

Actual applicability, long-term reliability, resistance to tampering, data authentication requirements, calibration procedures, interferences, and limitations must be evaluated by testing the instrumentation under controlled conditions during prolonged periods.

The user interface and data evaluation must be established. Because the purpose of the system is nuclear material accountancy, the main data to be evaluated are the uranium values for the various flows/process streams. The evaluation should be performed between two safeguards inspections in a monthly basis. The Coriolis and magnetic flow meters display the instantaneous flow rate (if a standalone display is included with the instrument). Therefore, the flow rate should be integrated to have the system display the total uranium flow. This integration can be taken care of during data acquisition. The proper media to store data and backup systems should also be investigated.

\subsection{GAMMA-RAY DETECTORS}

Regarding the recently developed portable HPGe and LaBr systems, some investigations are necessary in order to evaluate the performance of these systems in the field. To do so, specific analysis tools for safeguards applications need to be evaluated and appropriately integrated into the systems. 
APPENDIX A

COMPARISON OF IAEA SAFEGUARDS TECHNIQUES WITH THOSE SUGGESTED FOR AN NUCP 


\section{APPENDIX A}

\section{COMPARISON OF IAEA SAFEGUARDS TECHNIQUES WITH THOSE SUGGESTED FOR AN NUCP}

\begin{tabular}{|c|c|c|c|}
\hline Method & $\begin{array}{c}\text { IAEA } \\
\text { approved? }\end{array}$ & $\begin{array}{l}\text { Suggested } \\
\text { for NUCP? }\end{array}$ & Comments \\
\hline Gamma-ray spectrometry & Yes & No & See notes $1,2,3,14,21$ \\
\hline Neutron counting & Yes & Yes & See notes $1,20,21$ \\
\hline Destructive analysis & Yes & Yes & See notes 1, 4, 20, 24 \\
\hline Environmental sampling & Yes & Yes & See notes $1,4,5,16$ \\
\hline Surveillance & Yes & Yes & See notes $1,15,20,22$ \\
\hline Seals & Yes & Yes & See notes $1,6,20$ \\
\hline Unattended monitoring & Yes & Yes & See notes $1,7,13,20$ \\
\hline Remote monitoring systems & Yes & Yes & See notes $1,8,20$ \\
\hline \multicolumn{4}{|c|}{ Real-time monitoring (nonintrusive or intrusive in-line) } \\
\hline Flow or mass rate & No & Yes & $\begin{array}{l}\text { See notes } 9,14,17,18,19 \text {, } \\
21,23,24\end{array}$ \\
\hline Uranium concentration (photometric) & No & Yes & See notes $10,11,14,19,21$ \\
\hline Density & No & Yes & See notes $10,12,14,19,21$ \\
\hline Conductivity & No & Yes & See notes $10,12,14,19,21$ \\
\hline Temperature & No & Yes & See notes $10,12,14,19,21$ \\
\hline
\end{tabular}

\section{Notes}

1. A standard International Atomic Energy Agency (IAEA) safeguards technique.

2. IAEA uses this method for fission product detection and analysis; it is not applicable for natural uranium.

3. Low-energy gamma spectroscopy is used for uranium isotope decay and its daughters, but the selfshielding potential and long count times severely limit the practicability and application to a natural uranium conversion plant (NUCP).

4. IAEA has a laboratory for analyzing grab samples, verification samples, and/or environmental samples using standard destructive analysis techniques. Nondestructive analysis techniques, such as gamma-ray spectroscopy, are also used.

5. Although not discussed in the text, environmental sampling, including samples of soil, air, or waste streams, is a valuable tool that allows inspectors to look for suspicious activities.

6. Seals are routinely used on discrete containers (e.g., drums). This is a key technique used for uranium ore shipped to an NUCP and for uranium hexafluoride shipped from an NUCP. In addition, seals can be used internal to an NUCP for any containerized intermediate materials (e.g., uranium oxides,

7. uranium tetrafluoride).

8. Unattended monitoring is a key feature of the real-time monitoring suggested for an NUCP. IAEA does use unattended monitoring but currently not for uranium solutions.

9. Remote monitoring is a cheap and valuable tool used by IAEA; it usually uses video cameras stationed

10. on-site with feeds to monitors far away. Cameras can be placed at strategic locations to verify when equipment is operating.

11. Standard commercial equipment mounted on or in a pipeline to measure the volumetric flow rate of the liquid flowing through the pipe or a solids feed bin and/or solids transport device outfitted to measure the mass of solids transported with time. Use of this type of equipment is new for IAEA.

12. This technique is used for uranium solutions and is new to IAEA.

13. Photometric technique is used to directly measure dissolved uranium concentration.

14. One of the solution properties is used to indirectly calculate dissolved uranium concentration.

15. See Sect. 1 of the IAEA report Safeguards Techniques and Equipment, 2003 edition, International Nuclear Verification Series No. 1 (Revised), available at http://www-pub.iaea.org/MTCD/publications/PDF/NVS12003_web.pdf 